\title{
Sequence of Neuron Origin and Neocortical Laminar Fate: Relation to Cell Cycle of Origin in the Developing Murine Cerebral Wall
}

\author{
T. Takahashi, ${ }^{1,2}$ T. Goto, ${ }^{1,2}$ S. Miyama, ${ }^{1,2}$ R. S. Nowakowski, ${ }^{3}$ and V. S. Caviness Jr ${ }^{1}$ \\ ${ }_{1}^{1}$ Department of Neurology, Massachusetts General Hospital, Harvard Medical School, Boston, Massachusetts 02114 , \\ 2Department of Pediatrics, Keio University School of Medicine, Tokyo 160, Japan, and ${ }^{3}$ Department of Neuroscience and \\ Cell Biology, University of Medicine and Dentistry of New Jersey-Robert Wood Johnson Medical School, Piscataway, \\ New Jersey 08854
}

\begin{abstract}
Neurons destined for each region of the neocortex are known to arise approximately in an "inside-to-outside" sequence from a pseudostratified ventricular epithelium (PVE). This sequence is initiated rostrolaterally and propagates caudomedially. Moreover, independently of location in the PVE, the neuronogenetic sequence in mouse is divisible into 11 cell cycles that occur over a $6 \mathrm{~d}$ period. Here we use a novel "birth hour" method that identifies small cohorts of neurons born during a single $2 \mathrm{hr}$ period, i.e., $10-20 \%$ of a single cell cycle, which corresponds to $\sim 1.5 \%$ of the $6 \mathrm{~d}$ neuronogenetic period. This method shows that neurons arising with the same cycle of the 11 cycle sequence in mouse have common laminar fates even if they arise from widely separated positions on the PVE (neurons of fields 1
\end{abstract}

and 40) and therefore arise at different embryonic times. Even at this high level of temporal resolution, simultaneously arising cells occupy more than one cortical layer, and there is substantial overlap in the distributions of cells arising with successive cycles. We demonstrate additionally that the laminar representation of cells arising with a given cycle is little if at all modified over the early postnatal interval of histogenetic cell death. We infer from these findings that cell cycle is a neuronogenetic counting mechanism and that this counting mechanism is integral to subsequent processes that determine cortical laminar fate.

Key words: neocortical histogenesis; neuronogenesis; pseudostratified ventricular epithelium (PVE); cell cycle; neuronogenetic sequence; transverse neuronogenetic gradient
The laminar structure of the neocortex arises through a series of histogenetic processes that are initiated with neuronogenesis in a pseudostratified epithelium at the ventricular margin [pseudostratified ventricular epithelium (PVE); see Fig. 1] (Sauer, 1935; Sidman et al., 1959; Takahashi et al., 1995). Neuronogenesis is followed by neuronal migration (Rakic, 1972, 1978), assembly of neuronal somata into layers (Rice and van der Loos, 1977; Rakic, 1981), and reduction of neuronal number by histogenetic cell death (Finlay and Pallas, 1989; Verney et al., 1999).

Traditional pulse labeling "birthday" studies have established that sequence of origin is more or less correlated with laminar order. Thus, neurons destined for the deepest layer arise first, with cells destined for successively more superficial layers arising more or less in sequence thereafter (see Fig. $1 A$ ). For this reason, it has been hypothesized that proliferative mechanisms that determine sequence of origin are linked with those that determine the laminar fate of cells (Caviness, 1982; McConnell, 1989, 1991; McConnell and Kaznowski, 1991). A test of this hypothesis requires a criterion, independent of time (e.g., as measured in embryonic days), by which to define sequence of neuronogenetic order. Such a criterion is necessary because the sequence advances along a rostrolateral to caudomedial "transverse neuroge-

Received May 20, 1999; revised Sept. 10, 1999; accepted Sept. 10, 1999.

This work was supported by National Institutes of Health Grants NS12005 and NS33433, NASA Grant NAG2-750, and a grant from the Pharmacia Upjohn Fund for Growth and Development Research (T. T.). T.T. was supported by a fellowship of The Medical Foundation, Inc., Charles A. King Trust, Boston, MA. We gratefully acknowledge valuable suggestions and other assistance of Pradeep Bhide and Nancy Hayes.

Correspondence should be addressed to Takao Takahashi, Department of Pediatrics, Keio University School of Medicine, Tokyo 160, Japan. E-mail: tata@ med.keio.ac.jp.

Copyright (C) 1999 Society for Neuroscience 0270-6474/99/1910357-15\$05.00/0 netic gradient" (Hicks and D’Amato, 1968; Bisconte and Marty, 1975a; McSherry, 1984; McSherry and Smart, 1986; Bayer and Altman, 1991). Hence, corresponding events in the proliferative sequence occur at different times, with rostrolateral to caudomedial progression across the cerebral wall.

The cell cycle of origin is a suitable candidate criterion for progression of neuronogenetic sequence. We have previously established for the greater part of the transverse neurogenetic gradient in mouse that the neuronogenetic interval advances through a sequence of 11 cell cycles, and corresponding cycles are uniform in their kinetic and output parameters (Takahashi et al., 1995; Miyama et al., 1997).

For this analysis we exploit an innovative double S-phase labeling method (Takahashi et al., 1996a) (see Fig. 2) that specifies the "birth hour" of neurons at a 10 -fold or better temporal resolution than standard "birthdating." The method is applied for two reasons in neocortical fields 40 and 1 (see Fig. $1 C$ ). First, they lie at the rostrolateral (field 1) and dorsomedial (field 40) extremes of the transverse neuronogenetic gradient. Hence, corresponding events in the neuronogenetic sequence will occur in the PVE giving rise to these two fields at different times. Second, we have previously established the timing of advance of the 11-cycle sequence in the sectors of the PVE that give rise to each of these two fields (Takahashi et al., 1995; Miyama et al., 1997). Thus, in this analysis we are able to correlate for extreme positions in the transverse neuronogenetic gradient of the PVE the laminar destiny of neurons as a function of their cell cycle of origin.

\section{MATERIALS AND METHODS}

Sequential S-phase labeling

We have devised in mouse a sequential S-phase labeling schedule using a single pulse of tritiated thymidine $\left({ }^{3} \mathrm{H}-\mathrm{TdR}\right)$ followed by cumulative 
label with bromodeoxyuridine (BUdR) (Takahashi et al., 1996b) that marks cohorts of neurons arising in synchrony during a $2 \mathrm{hr}$ interval as ${ }^{3} \mathrm{H}$-TdR-only-labeled cells (see Figs. 2, 3). Cells, which are either in $\mathrm{S}$ phase at the end of the $2 \mathrm{hr}$ interinjection interval or which re-enter $\mathrm{S}$ during a subsequent cell cycle, become labeled with BUdR and hence are not counted. Thus, the method, which is independent of the availability time of the tracers (Hayes and Nowakowski, 1999), specifies literally the birth hour and not only the birthday of neuron cohorts. Such cohorts represent $2 \mathrm{hr} / T_{\mathrm{C}} \times 100 \%$ ( $T_{\mathrm{c}}$, total cell cycle duration) of the total output of a single cell cycle. Given that $T_{\mathrm{c}}$ increases as neuronogenesis proceeds (Takahashi et al., 1992, 1995, 1996a; Cai et al., 1997), $2 \mathrm{hr} / T_{\mathrm{C}} \times$ $100 \%$ varies from $\sim 20 \%$ [embryonic day (E) 12 or E12-E13] to $10 \%$ (E15-E16). Because there are 11 cell cycles during the $6 \mathrm{~d}$ neuronogenetic interval in mouse, one cell cycle is $1 / 11$ or $\sim 9 \%$ of the total number of cell cycles of neuronogenesis. Therefore, the "temporal resolution" of the $2 \mathrm{hr}$ cohort labeling method used in this analysis will be $9 \times 10-20 \%$ or $\sim 1-2 \%$ of the total neuronogenetic interval in mouse.

In contrast, the maximum possible temporal resolution of the standard ${ }^{3} \mathrm{H}$-TdR pulse is $\left(T_{\mathrm{s}}+\right.$ Clearance $) / T_{\mathrm{c}}$, where $T_{\mathrm{s}}$ is the length of $\mathrm{S}$ phase and "Clearance" is the clearance time for ${ }^{3} \mathrm{H}-\mathrm{TdR}$, which for long survivals is several hours, i.e., approximately the length of S (Hayes and Nowakowski, 1999). In mouse this varies from $80-100 \%$ of the cell cycle at E11 to $40-50 \%$ of the cell cycle at E16 (Takahashi et al., 1995). Moreover, in practice the resolution of the standard ${ }^{3} \mathrm{H}-\mathrm{TdR}$ pulse method in mouse is substantially less than a single cell cycle because labeled cells have a wide number of silver grains, indicating that they arise from several cell cycles in sequence after the exposure to ${ }^{3} \mathrm{H}-\mathrm{TdR}$ (Angevine, 1965; Sidman, 1970; Polleux et al., 1997a). Thus, the standard birthday methods may have a resolution of two to three cell cycles or $\sim 20-30 \%$ of the total neuronogenetic interval, i.e., $>10$ times less resolution than the $2 \mathrm{hr}$ cohort method. In the rhesus monkey (Rakic, 1974), where cell cycles are known to be severalfold longer than the cycles in rodents, a cohort of ${ }^{3} \mathrm{H}-\mathrm{TdR}$ heavily labeled cells will represent a lower fraction of the total output of a single cell cycle than in rodents ( $\sim 25 \%$ at $\mathrm{E} 40$ at the outset of neuronogenesis) (Kornack and Rakic, 1998). Furthermore, there may be approximately 28 cell cycles during a 2 month neocortical neuronogenetic interval in monkey, so that one cell cycle is $<4 \%$ of the total number of cell cycles occurring in the course of neuronogenesis (Caviness et al., 1995). Therefore, the approximate temporal resolution of the standard ${ }^{3} \mathrm{H}$-TdR pulse will be $4 \times 25 \%$ or $1 \%$ of the total neuronogenetic interval in monkey. Thus, this doublelabeling cohort method in mice and the standard ${ }^{3} \mathrm{H}-\mathrm{TdR}$ pulse method in monkey may be expected to sample comparable portions of the neuronogenetic interval in the two species. There is the additional advantage that this method permits a quantitative estimate of the total output of the cell cycle represented by each cohort.

\section{Animals and procedures}

CD1 mice were maintained on a 12 hr (7:00 A.M.-7:00 P.M.) light/dark schedule. Conception was ascertained by the presence of a vaginal plug (the day of conception $=\mathrm{E} 0)$. Intraperitoneal injections of ${ }^{3} \mathrm{H}-\mathrm{TdR}(5$ $\mu \mathrm{Ci} / \mathrm{g}$ body weight) were given at 7:00 A.M. to separate sets of dams on E11-E16 (see Fig. 2). Beginning at 9:00 A.M., BUdR injections $(50 \mu \mathrm{g} / \mathrm{g}$ body weight) were given at $3 \mathrm{hr}$ intervals through a period greater than $T_{\mathrm{C}}-T_{\mathrm{S}}$ determined previously for the respective embryonic date.

The pregnancy was allowed to continue to term, and pups were maintained until postnatal day 22 (P22), when they were anesthetized with ether and perfused via the left ventricle with $70 \%$ alcohol for $3 \mathrm{~min}$. They were dehydrated and embedded in paraffin and sectioned coronally at $4 \mu \mathrm{m}$ (Takahashi et al., 1992, 1993, 1994) and stained immunocytochemically for BUdR using DAB as a chromogen (Takahashi et al., 1992, 1994). After immunohistochemistry the slides were dipped in Kodak NTB2 nuclear emulsion and kept at $4^{\circ} \mathrm{C}$ for 6 weeks. They were developed and counterstained with $0.1 \%$ basic fuchsin.

For animals exposed on each of the embryonic dates E11-E16, the analysis was performed on data collected from the brains of four animals, two from each of two different litters. In each animal, "standard sectors" subjected to analysis in fields 1 and 40 were all specified to be $250 \mu \mathrm{m}$ in medial to lateral dimension (in a coronal section) and $4 \mu \mathrm{m}$ in depth, corresponding to section thickness. With respect to the height or radial dimensions of the sector, each was subdivided into radial bins, $25 \mu \mathrm{m}$ in height, with the bins numbered 1,2,3, and so on from the pial surface inward (Takahashi et al., 1996b). The number of ${ }^{3} \mathrm{H}-\mathrm{TdR}-$ only-labeled nuclei was counted for each bin. Because the height or radial dimensions of the cortex in the two fields varied modestly, bin position in the cortex was normalized by conversion to percentile height where percentile height for bin $n=(n / N) \times 100$, where $N$ is the total number of bins within the cortex. The number of ${ }^{3} \mathrm{H}$-TdR-only-labeled nuclei was then assigned to appropriate percentile height where the height of the cortex was divided into 205 -percentile steps. For each brain the location of cortical laminar boundaries was also specified with respect to this normalized adjustment of cortical height so that ${ }^{3} \mathrm{H}$-TdR-only-labeled nuclei could be assigned to layers as well as to counting bins.

\section{Cohort distribution}

For each of the labeled cohorts at each embryonic date, E11-E16, a "specimen weighted" distribution of cells by density across the height of the cortex was calculated using the following three-step procedure.

(1) Number of cells per bin (i.e., per 5-percentile step) per brain. First, the total number of ${ }^{3} \mathrm{H}$-TdR-only-labeled nuclei in corresponding bins was counted and summed as the total for that bin for each brain. (Counts were not undertaken for cells with ${ }^{3} \mathrm{H}-\mathrm{TdR}+\mathrm{BUdR}$ or BUdR-only labeling patterns because of their large numbers.) For the E12-E16 cohorts, labeled nuclei were relatively abundant (a total of 1980 cells were counted in the full set of specimens), so these distributions were based on eight sections per brain for four brains. For the E11 cohort in field 40, there were relatively few labeled cells (only 25 cells were counted in four brains), so these distributions were based on counts made in 20 sections per brain.

(2) Average percentile per bin per brain. For each brain the number of nuclei per bin was divided by the total number of nuclei counted for that brain. The percentiles for corresponding bins were then averaged across the four brains of each embryonic age to give average percentile per bin per brain.

(3) Normalized distributions. To enable comparisons of distributions across the full set of embryonic ages, the percentiles per bin per brain were normalized to produce the average number of nuclei per bin per section. For this distribution, the average percentile per bin per brain for the cohorts at each embryonic age was multiplied by the total number of nuclei counted in all of the specimens of that age and then divided by the number of sections used to obtain the average (i.e., 32, except at E11 when 80 was used). This normalized distribution for each cohort had units of "number of nuclei per bin per section."

The specimen-weighted procedure was used to minimize the variation that might be produced from specimen-related parameters, i.e., processing differences, slight age differences, plane of section, etc. We also calculated an "overall" distribution in which every labeled nucleus had equal weight, regardless of the specimen in which it occurred. The overall and specimen-weighted distributions were virtually identical.

\section{Distributions for each cell cycle}

The final average distribution (from the preceding paragraph; see Fig. $4 A$ ) represents the number of cells per $2 \mathrm{hr}$ cohort which is only $2 / T_{\mathrm{C}}$ of the entire output for a single cell cycle. Because $T_{\mathrm{C}}$ is known to vary during the neuronogenetic interval, for comparison, each of these distributions was used to estimate the total number of cells that comprises the output for the entire cycle of which the cohort was a part. This was performed by multiplying each bin of each distribution by $T_{\mathrm{c}} / 2$, where $T_{\mathrm{C}}$ for each embryonic day for fields 1 and 40 was taken to correspond to values estimated previously for the dorsomedial cortical zone (DCZ) and lateral cortical zone (LCZ), respectively, of the PVE (Miyama et al., 1997) (see Fig. 4B). Normal approximations for each distribution were calculated using a least-squares fitting method (Takahashi et al., 1996b) (see Fig. 4C).

The location of each $2 \mathrm{hr}$ cohort within the 11-cell cycle sequence was designated in terms of the fraction of the specific cycle that has been completed in that cortical area (Takahashi et al., 1995; Miyama et al., 1997). Thus, for example, if cycle status is designated cycle 6.9, it is meant that the reference population will have completed $90 \%$ of the seventh cycle in the series of 11 cycles (Takahashi et al., 1995; Miyama et al., 1997). Linear interpolation of the normal approximation parameters (i.e., mean position, amplitude, and standard deviations) were used to estimate the distribution of cells at each integer cell cycle (see Fig. 4D). Interpolations for integer cell cycles before E12 (for field 1) or E11 (for 40) and after E16 (for fields 1 and 40) used an "imaginary" population of zero size positioned at the border with the white matter or at the layer I border with a similar standard distribution to the nearest "real" population. All calculations were performed with Microsoft Excel. 


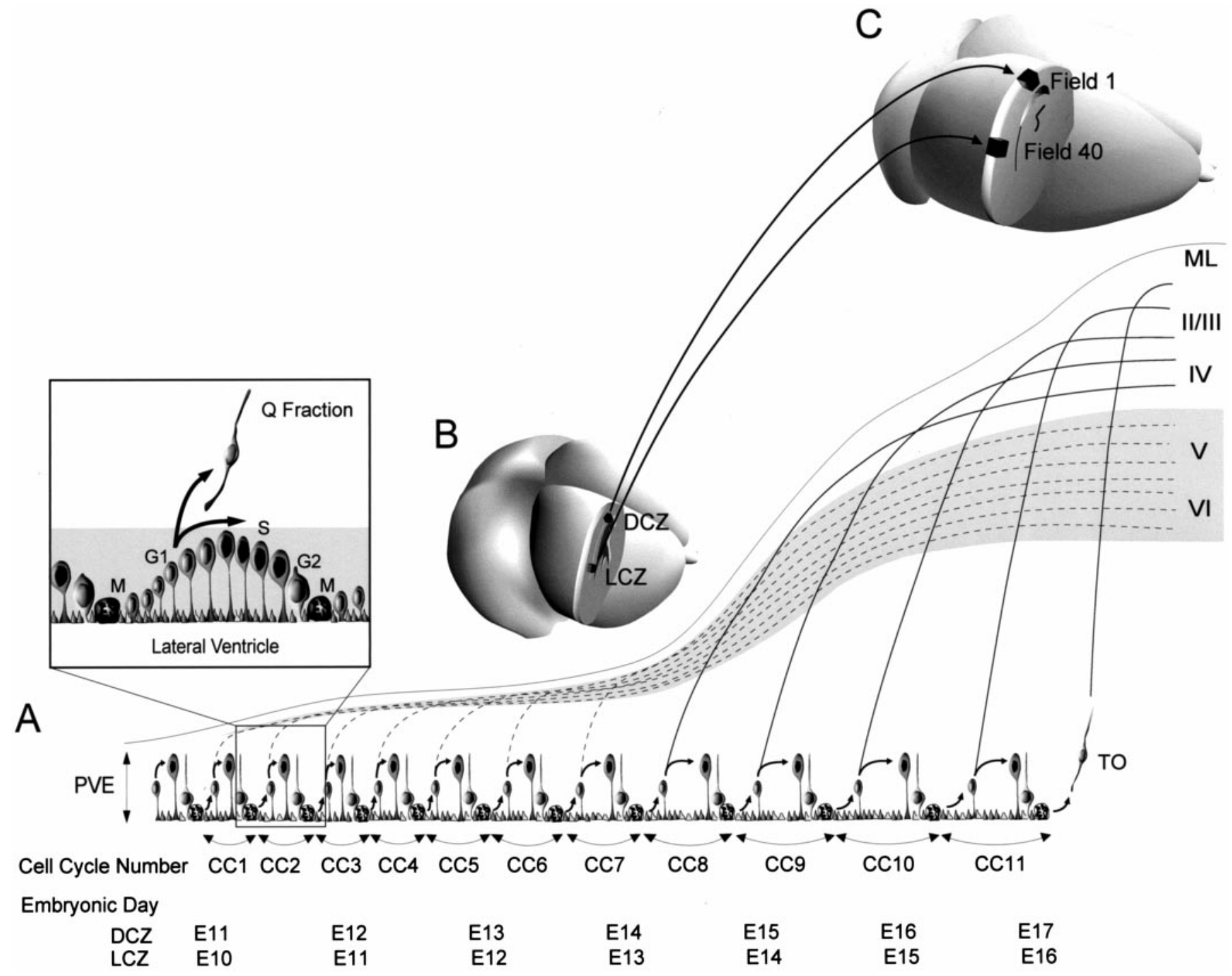

Figure 1. Neuronogenesis in the pseudostratified ventricular epithelium $(P V E)$ in relation to the "inside-out pattern" of neocortical layer formation. $A$, The founder proliferative populations and their progeny in both dorsomedial $(D C Z)$ and lateral $(L C Z)$ cortical zones of the PVE execute 11 cell cycles (CC1-CC11) over the course of the $6 \mathrm{~d}$ neuronogenetic interval, continuing from the eleventh (E11) embryonic day through E17 in the DCZ and E10 through E16 in the LCZ. The cycle sequence is initiated earlier and remains advanced by $\sim 24 \mathrm{hr}$ in LCZ relative to DCZ (note for each cell cycle, a $24 \mathrm{hr}$ difference in time of occurrence of corresponding cell cycles in DCZ and LCZ). The first neurons to arise from either region of the PVE are destined for the deepest cortical layers (dotted curved lines connecting the $P V E$ and layers $V I$ and $V$ ), whereas progressively later forming neurons are destined for progressively more superficial layers (solid curved lines connecting the $P V E$ and layers $I V$ and $I I / I I I$ ). The daughter cells arising from cycle 11 are the terminal output (TO) of neuronogenesis. Curved arrows in the PVE show interkinetic nuclear migration through $G 1, S, G 2$, and $M$ phases of the cell cycle. Interkinetic nuclear migration is shown for $C C 2$ in the magnified view in the inset in top left. A fraction of postmitotic cells $(Q)$ leaves the PVE with each cycle and migrates toward the surface of the hemisphere as young neurons. $B, C, D C Z$ and $L C Z$ of the PVE of the embryonic cerebral hemisphere $(B$, coronal cutaway) give rise (curved arrows connecting $B$ and $C$ ) to neurons destined, respectively, for fields 1 and 40 in the adult hemisphere ( $C$, coronal cutaway).

\section{RESULTS}

The present analysis maps the final intracortical distributions of cohorts of cells arising from the murine neocortical PVE over each of the successive E11-E16. Cohorts produced during a $2 \mathrm{hr}$ period are mapped at P22 with respect to cortical height and neocortical layer in both the posterior medial region of the somatosensory I (SI) (field 1) and SII (field 40) representations (Fig. 1B) (Caviness, 1975). For both fields 1 and 40 we have followed the standard six-layer convention for neocortical lamination but have combined layers II and III as a single layer because layer II is typically either very narrow or even indistinguishable as a separate layer in the mouse neocortex (Caviness, 1975).
The analysis exploits the fact that in the same coronal histological section cohorts distributed to fields 1 and 40 and arising at the same embryonic date will have arisen from quite different cell cycles (Miyama et al., 1997) (Fig. 1A). We have previously determined from the patterns of alignment of radial glial fibers (Misson et al., 1991) that field 1 receives its neuronal complement principally from DCZ and field 40 from LCZ of the PVE (Fig. $1 B, C$ ) (Miyama et al., 1997). The additional evidence established in this analysis is that the neuronogenetic interval giving rise to neurons of field 1 continues from early E11 (with the labeling paradigm used here, ${ }^{3} \mathrm{H}$-TdR-only-labeled cells were first observed on this date) to early E17 (the last date ${ }^{3} \mathrm{H}$-TdR-onlylabeled nuclei were observed). This corresponds to the neurono- 


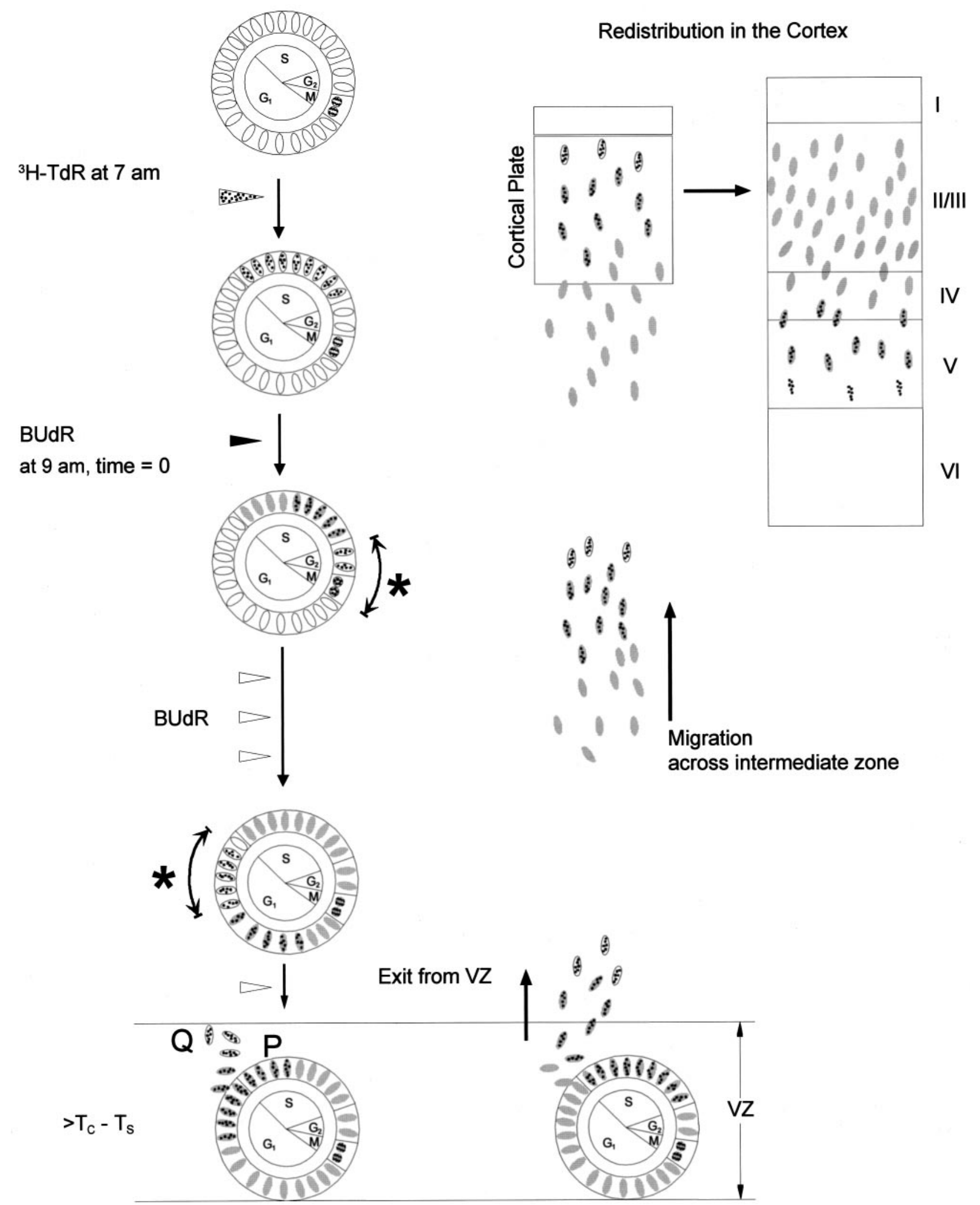

Figure 2. Labeling schedule for the birth hour of a $2 \mathrm{hr}$ cohort. Proliferative cells in the PVE within the ventricular zone (VZ) are asynchronously distributed through G1, S, G2, and $M$ phases of cell cycle (top, left panel, open eclipses lined up inside the circle; M phase nuclei are shown as open circles with two zigzag lines). The PVE was exposed initially at 7 A.M. to ${ }^{3} \mathrm{H}-\mathrm{TdR}$ (arrowhead with "silver grains"), which was followed in 2 hr by BUdR ( filled arrowhead). Cells that exit S-phase in the $2 \mathrm{hr}$ interval between these exposures, and their postmitotic progeny, will be labeled with ${ }^{3} \mathrm{H}-\mathrm{TdR}$ but not BUdR (white nuclei with grains). They are readily distinguished in autoradiograms (a curved arrow with an asterisk $=2 \mathrm{hr}$ cohort) from cells labeled in $\mathrm{S}$ phase by both ${ }^{3} \mathrm{H}-\mathrm{TdR}$ and BUdR (dark nuclei with grains) or cells labeled only by BUdR (dark nuclei with no grains). BUdR injections were continued (open arrowheads) for a time longer than the combined duration of $G 2, M$, and $G 1$ phases of the cell cycle (i.e., $>T_{\mathrm{C}}-T_{\mathrm{S}}$ ) (Figure legend continues) 


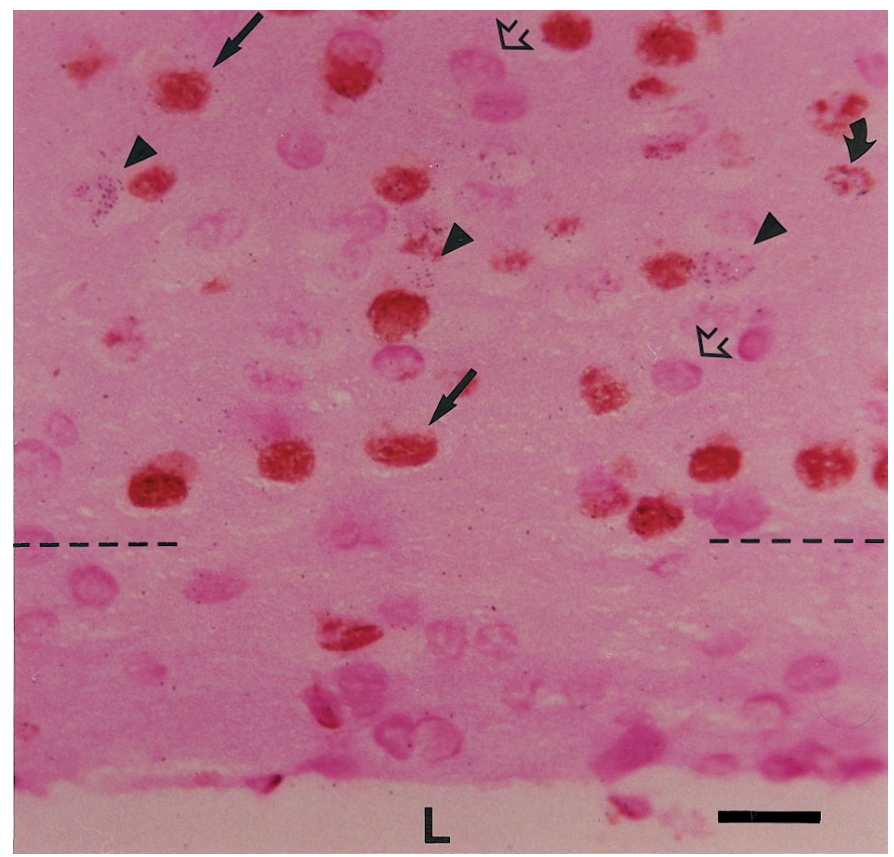

Figure 3. Distribution of the E13 cohort in field 1. A cohort of cells leaving S phase in synchrony over the $2 \mathrm{hr}$ interval between 7 and 9 A.M. on E13 were marked by the sequential ${ }^{3} \mathrm{H}$-TdR-BUdR exposure schedule described in Figure 2. The $Q$ fraction of the postmitotic daughter cells of this cohort (arrowheads, cells labeled only with ${ }^{3} \mathrm{H}-\mathrm{TdR}$ ) are distributed over the height of layer VI in field 1. Filled arrows, Cells labeled only with BUdR; curved arrows, cells labeled with both ${ }^{3} \mathrm{H}-\mathrm{TdR}$ and BUdR; open arrows, nonlabeled cells. Dotted line marks the white matter/layer VI boundary. $L$, Lateral ventricle. Scale bar, $10 \mathrm{um}$.

genetic interval in DCZ, whereas the neuronogenetic interval for field 40 continues from late on E10 through E16 corresponding to the neuronogenetic interval of LCZ.

\section{Cohorts by day of origin}

\section{Similarities in cohort distribution in fields 40 and 1}

The labeled cohort of cells born within a $2 \mathrm{hr}$ interval can be readily identified as being labeled only with ${ }^{3} \mathrm{H}-\mathrm{TdR}$ (Fig. 3, arrowheads). The number of cells in each $2 \mathrm{hr}$ cohort is relatively small, and in the cortex as a whole, as expected (see Materials and Methods), the number of cells doubly labeled with both ${ }^{3} \mathrm{H}-\mathrm{TdR}$ and BUdR (Fig. 3, curved arrowhead) is much greater than the number of cells in the $2 \mathrm{hr}$ cohort. Because the total number of ${ }^{3} \mathrm{H}-\mathrm{TdR}$ (singly labeled plus doubly labeled) corresponds to a "standard" ${ }^{3} \mathrm{H}-\mathrm{TdR}$ birthday experiment, the small number of cells in the $2 \mathrm{hr}$ cohort confirms the high temporal resolution of the method.

On day of E11-E16, the $2 \mathrm{hr}$ cohort is distributed across a limited span of the cortical height of fields 40 and 1 (Figs. 3, 4A). In both cortical fields the earliest arising cohort occupies the deepest cortical laminae, and the latest arising cohort occupies the most superficial cortical laminae. This pattern, in confirmation of previous investigations in all mammalian species (Angevine and Sidman, 1961; Hicks and D'Amato, 1968; Fernandez and
Bravo, 1974; Rakic, 1974; Caviness, 1982; Luskin and Shatz, 1985; Bayer and Altman, 1991), is evident whether illustrated from the perspective of the distribution of a cohort in single animals (Fig. 5) or from the mean distributions of the cohort across sets of animals (Fig. 4A). A systematic shift from deep to superficial positions in the cortex is evident with each successive cohort, both with respect to the mean and median position of the labeled cells and also with respect to their range of distributions (Fig. 6).

Although each $2 \mathrm{hr}$ cohort is a sampling of $<10 \%(=2 / 24 \mathrm{hr})$ of the output of its respective day of origin, there are no "gaps" between adjacent distributions. Indeed, the full sequence of cohorts arising successively on E11-E16 within both field 40 and field 1 comprises a set of overlapping distributions that, taken together, span the full height of the cortex (Figs. 4A, 6). Although the fraction of the cortical wall subtended by a single $2 \mathrm{hr}$ cohort is substantial, it is smaller, as expected, than the fraction of the cortical wall subtended by cells labeled by a single "pulse" of ${ }^{3} \mathrm{H}-\mathrm{TdR}$ in a traditional birthday analysis (Bisconte and Marty, 1975b; Caviness, 1982; Bayer and Altman, 1991; Polleux et al., 1997a,b).

\section{Differences in cohort distribution in fields 40 and 1}

Cells with the same embryonic day of origin are distributed more superficially in field 40 than in field 1 (Figs. $4 A, 6 A$ ), a difference to be expected given the substantial distance up the transverse neuronogenetic gradient of field 40 with respect to field 1 (Bayer and Altman, 1991; Miyama et al., 1997). The superficial shift in cohort distributions in field 40 with respect to field 1 on E14 is much greater than that in cohorts arising on E13 and earlier and in cohorts arising on E15 and later (Fig. 6A). The distribution of cells of the E14 cohort in field 40 is limited almost completely to layer IV, whereas in field 1 cells of this same cohort are limited almost entirely to layers VI-V (Fig. 4A). This confirms the earlier observations in mouse by Smart (Smart and McSherry, 1982; Smart and Smart, 1982) that movement up or down the transverse neuronogenetic gradient (as lateral to medial or medial to lateral) through the cortex is associated with only moderate differences in distribution of cells of a given date of origin when the distribution is centered over layers VI or II/III but with substantial differences in such distributions when the distributions are centered over layers V-IV.

This difference in layer destination in fields 40 and 1 of neurons arising on the same embryonic day underscores the long established observation that there are systematic shifts in time of enactment of corresponding proliferative events across the PVE (Hicks and D'Amato, 1968; Smart and McSherry, 1982; McSherry, 1984; Bayer and Altman, 1991). Judging from the finding that the midcortical distribution of the E13 cohort in field 40 is the same as that of the E14 cohort in field 1 (Fig. $4 A$ ), it would appear that the sector of PVE giving rise to field 40 is advanced $\sim 24 \mathrm{hr}$ with respect to the sector giving rise to field 1 . This is consistent with a $24 \mathrm{hr}$ advance in the proliferative process in LCZ with respect to DCZ (Fig. $1 A$ ), which was established to be the case in an earlier analysis based on independent methods (Miyama et al., 1997).

so that postmitotic cells reentering $\mathrm{S}$ phase ( $P$ or $P$ fraction) will become marked with BUdR (bottom left, dark nuclei with grains under the letter $P$ ). The postmitotic daughter cells that leave the cycle $\left(Q\right.$ fraction of the original $2 \mathrm{hr}$ cohort) may be recognized subsequently as cells labeled only by ${ }^{3} \mathrm{H}-\mathrm{TdR}$ (bottom left, white nuclei with grains, next to the letter $Q$ ). At P22, long after their migrations across the intermediate zone to the CP and redistribution in the cortex, their locations with respect to layers I-VI within fields 1 and 40 are mapped from autoradiograms. 
Field 1

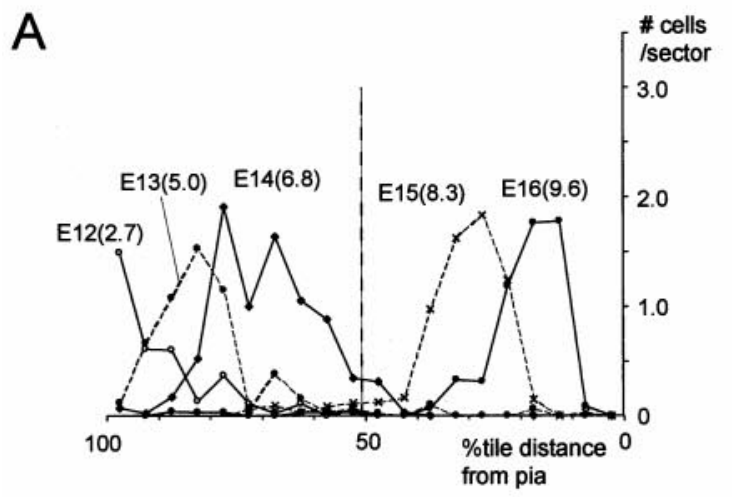

Field 40

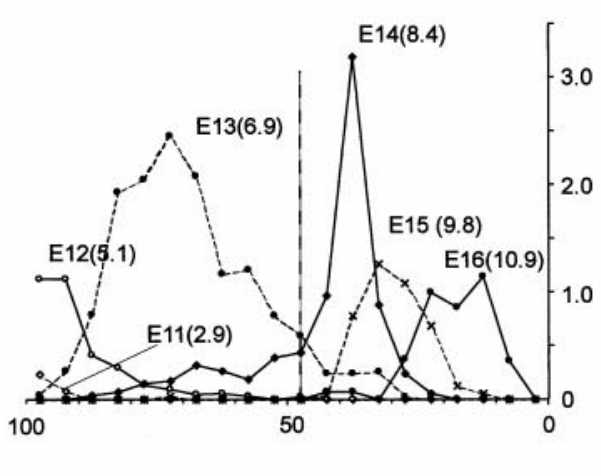

B

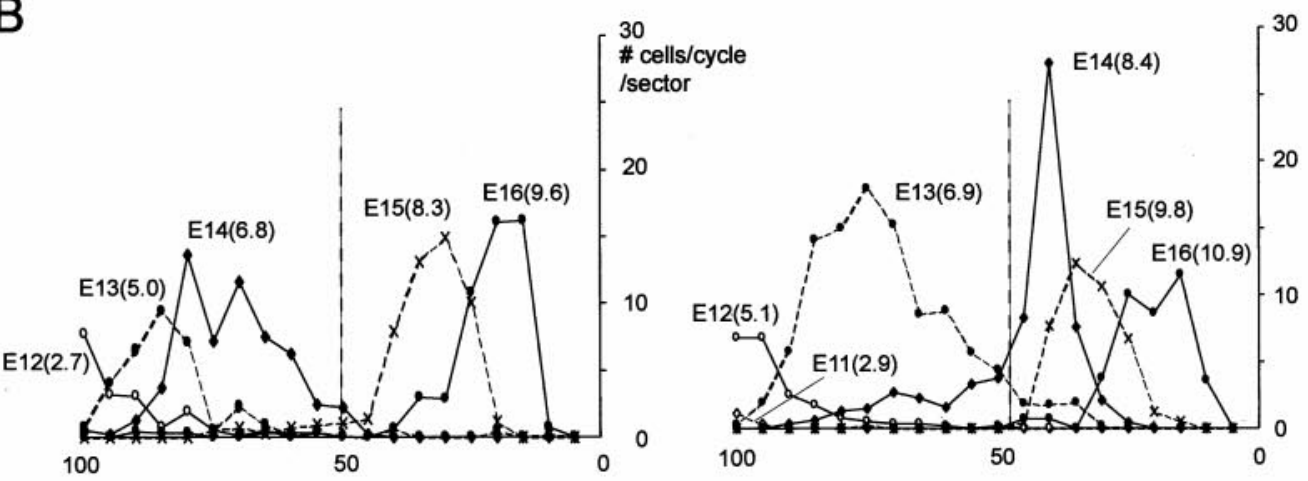

C

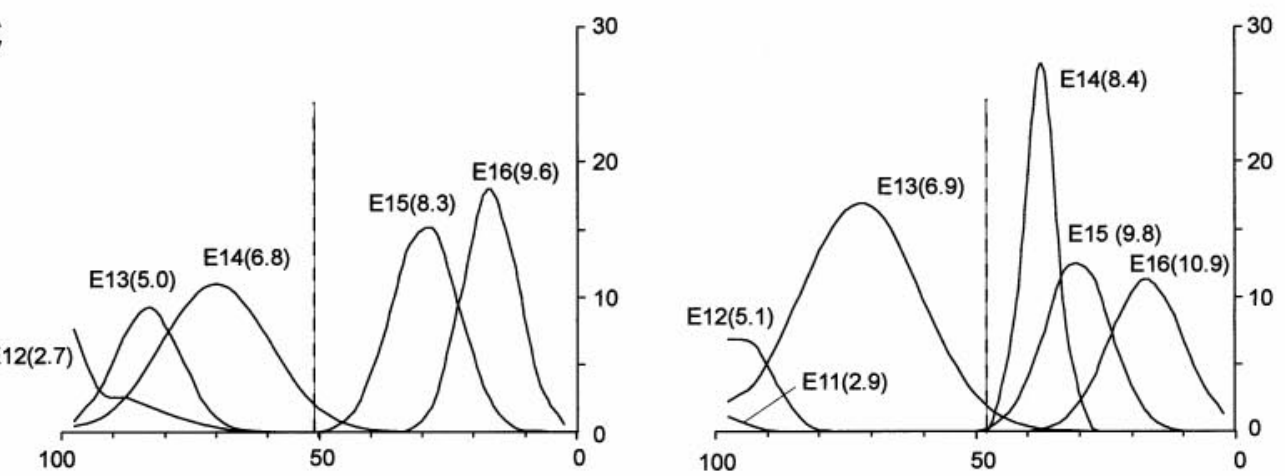

D
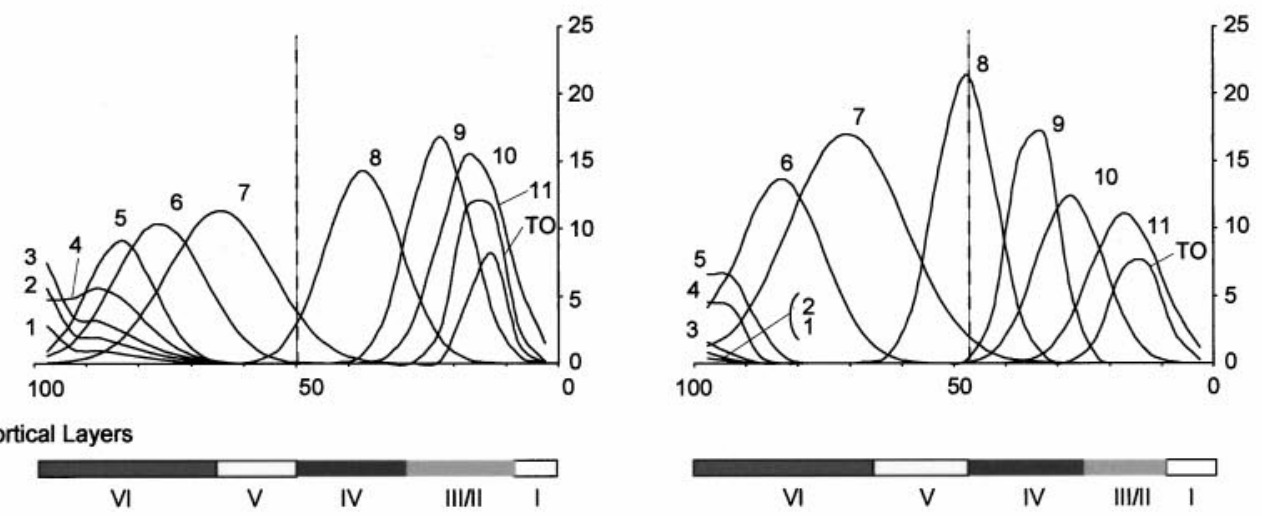

Figure 4. Distributions within fields 1 (left) and 40 (right) of neuronogenetic output with respect to both embryonic days and cell cycles. For each plot, the height of fields 40 and 1 have been normalized as a percentile (abscissa), and the projection of the cortical layer has been scaled appropriately to each field. The shaded bars at the bottom indicate the borders of each of the cortical laminae. A vertical dotted line in each of the graphs marks the boundary between layers V and IV (also see Materials and Methods). A, The positions of cells of $2 \mathrm{hr}$ cohorts, labeled on each of (Figure legend continues) 


\section{Embryo-to-embryo variation in cohort distribution in fields 40} and 1

Animals from the same litter may differ by as much as $20 \mathrm{hr}$ in their relative maturities (Theiler, 1972; Smart and Smart, 1982). We evaluate here whether the temporal resolution of the $2 \mathrm{hr}$ cohort method is sufficiently sensitive to detect possible differential maturity in embryos of the same litter expressed as slight differences in cohort distribution (Fig. 5). Observations are based on cohort distributions in four embryos at each age, two animals from each of two litters. With the exception of the cohorts arising on E13 (field 40) and E14 (field 1), the intracortical distributions at each age in both fields 1 and 40 are substantially overlapping and virtually indistinguishable in all four specimens. At E13 (field 40) and E14 (field 1), however, there are slight differences in the deep to superficial order of the peak densities across midcortical layers. We infer that these slight differences in distribution of these cohorts reflect relatively small differences in sequence of origin caused by small differences in relative maturity, evident even in comparison of the paired animals from the same litters. That embryo-to-embryo differences should be most readily evident in this way at E13 (field 40) and E14 (field 1) is to be expected. This is because relatively small differences in sequence of origin are associated with relatively large differences in laminar distribution (see Differences in cohort distribution in fields 40 and 1), particularly for the midcortical layers that are formed on E13 in field 40 and on E14 in field 1. The relative uniformity in distribution overall is presumed to reflect the selection of embryos that were at similar stages of maturity.

\section{Cohort distribution at P0 as compared with that at P22}

The original cycle output sampled by a $2 \mathrm{hr}$ cohort will have been reduced by histogenetic cell death by $\mathrm{P} 22$, a process that appears largely to run its course by the end of the second postnatal week in mice and rats (Leuba et al., 1977; Finlay and Slattery, 1983; Finlay and Pallas, 1989; Ferrar et al., 1992; Miller, 1995; Spreafico et al., 1995; Verney et al., 1999). Thus, the cohort sample at P22 (Fig. $4 A, B)$ represents the net total of output and cell death. Where we use the expression "net output" in the context of this manuscript, it is understood that what is intended is the net contribution or output by cycle followed by cell death. To estimate the qualitative contribution of cell death to the distribution of the cohorts, we examined the distribution patterns of each of the E13-E15 cohorts at P0 in each of the fields 1 and 40 (Fig. 7). Only the general shape and location of the distributions can be compared, because at P0 the cortical plate (CP) (Fig. 7, between the two arrowheads), which is still narrow (because the neuropil has not yet expanded), corresponds to layers II/III-IV in the P22 cortex (at approximately the 50-percentile in Fig. 4). With this limitation in mind, it can be seen that the distributions of each 2 hr cohort at E13, E14, and E15 in both fields 1 and 40 at P0 (Fig.
7) are essentially identical to that at P22 (Fig. 4A). The closeness of distributions of the same cohort in the same field at the two ages ( $\mathrm{P} 0$ and $\mathrm{P} 22$ ) applies for the relative position of the peak of the distribution at the two ages with respect to V/IV border and importantly also for the relatively wide and low density distribution of the "shoulders" of the cohort. Specifically, the E13 peak falls in the lower half of layer VI/V, the E14 peak falls below the $\mathrm{V} / \mathrm{IV}$ border in field 1 but above it in field 40, and the E15 peak falls well within the supragranular layers (compare Fig. $4 A, B$ with Fig. 7). The largest apparent discrepancy between the distributions at P0 (Fig. 7) and at P22 (Fig. 4A,B) is that the overlap of the E13 and E14 distributions at $\mathrm{P} 0$ seems to be greatly reduced from P22. This discrepancy is only apparent, however, and is well within the embryo-to-embryo range seen in Figure 5. Overall, therefore, these observations indicate that the "laminar footprint" of a cohort of cells, that is, the span of laminae through which a cohort is distributed, established before cell death, is not appreciably altered by cell death.

\section{Magnitude of cohort dispersion}

The degree of dispersion within neocortical layers of the sampled 2 hr cohorts may be characterized quantitatively. For this determination (see Materials and Methods) the output of the full set of 11 neuronogenetic cycles is considered to be distributed to layers I-VI, taken here to correspond to $100 \%$ of height of the cortex. Here we have ignored the relatively minor neuron distribution of a portion of the E11 cohort to the subplate in mouse, which is eventually largely eliminated by histogenetic cell death (Verney et al., 1999). The $2 \mathrm{hr}$ in which each of the labeled cohorts is formed correspond to $1.5 \%$ of the total neuronogenetic interval. If sequence of production alone were sufficient to specify cortical position, then each $2 \mathrm{hr}$ cohort would occupy $1.5 \%$ of the cortical thickness. This is clearly not true (Figs. 4A), and if we consider the $95 \%$ range of intracortical distribution for the normalized fits, each is distributed through $\sim 22-56 \%$ of cortical height (a mean of $41 \%$ ) (Fig. 6). That is, the distribution of the output of only $1.5 \%$ of the neuronogenetic interval is dispersed to an average of $41 \%$ and perhaps as much as $56 \%$ of the cortical thickness. This represents a dilution in dispersion of 27 -fold (i.e., 41/1.5\%) to possibly as much as 37 -fold (i.e., 56/1.5\%) of the $2 \mathrm{hr}$ cohort. Although dispersion is greater in the middle of the neuronogenetic interval than at its beginning and end, this difference is relatively minor. Exceptions to this broad dispersion of neurons are encountered only with the earliest arising cohort. Thus, the intracortical range of distribution of the E11 cohort, the earliest sampled, is only $5 \%$ of the cortical height. Observe, also, that there are only a few cells in this cohort; we presume that most of the remainder of the cells of this cohort were destined for the subplate and eliminated by histogenetic cell death (Verney et al., 1999).

\footnotetext{
embryonic days. The average number of cells of each cohort observed in a standard coronal sector per section is given on the ordinate. The individual cohorts are identified with respect to both their embryonic day of origin (E11-E16) and their cell cycle of origin (in parentheses after embryonic date). Note that cells of an E11 cohort are detected in field 40 but not in field 1. In field 40 the E11 cohort arises near the completion of cycle 3 (at cycle 2.9). $B$, The plot of $2 \mathrm{hr}$ cohort distribution represented in $A$ is transformed to output of corresponding cell cycle by multiplying the number per cohort by $T_{\mathrm{C}} / 2 \mathrm{hr}\left(T_{\mathrm{c}}=\right.$ cell cycle length in hours) for the respective cycle. Note that the form of each distribution in plots $A$ and $B$ is the same but that the number of cells per distribution on the ordinate in $B$ is larger than in $A$, and the relative heights are changed because of the lengthening of the cell cycle. For $A-D$, the distributions represent "net output," that is, the populations remaining after cell death (Verney et al., 1999). $C$, For each of the distributions plotted in $B$, a "best fit" normal distribution was calculated. These normal distributions account for virtually all of the variance seen in $B$; see Results. $D$, The contribution of the output of each of the full 11-cycle series is reconstructed as normal distribution by interpolation from the curves shown in $C$. Note that a portion of the output of cycles $1-5$ is not represented within the six layers of the cortex and is assumed to have contributed to the subplate and been eliminated by cell death. TO refers to the terminal output after cycle 11 (Takahashi et al., 1996a).
} 
Field 1

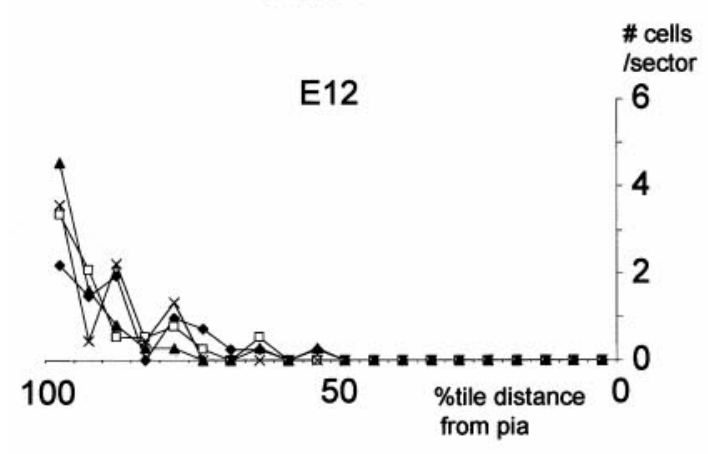

E13
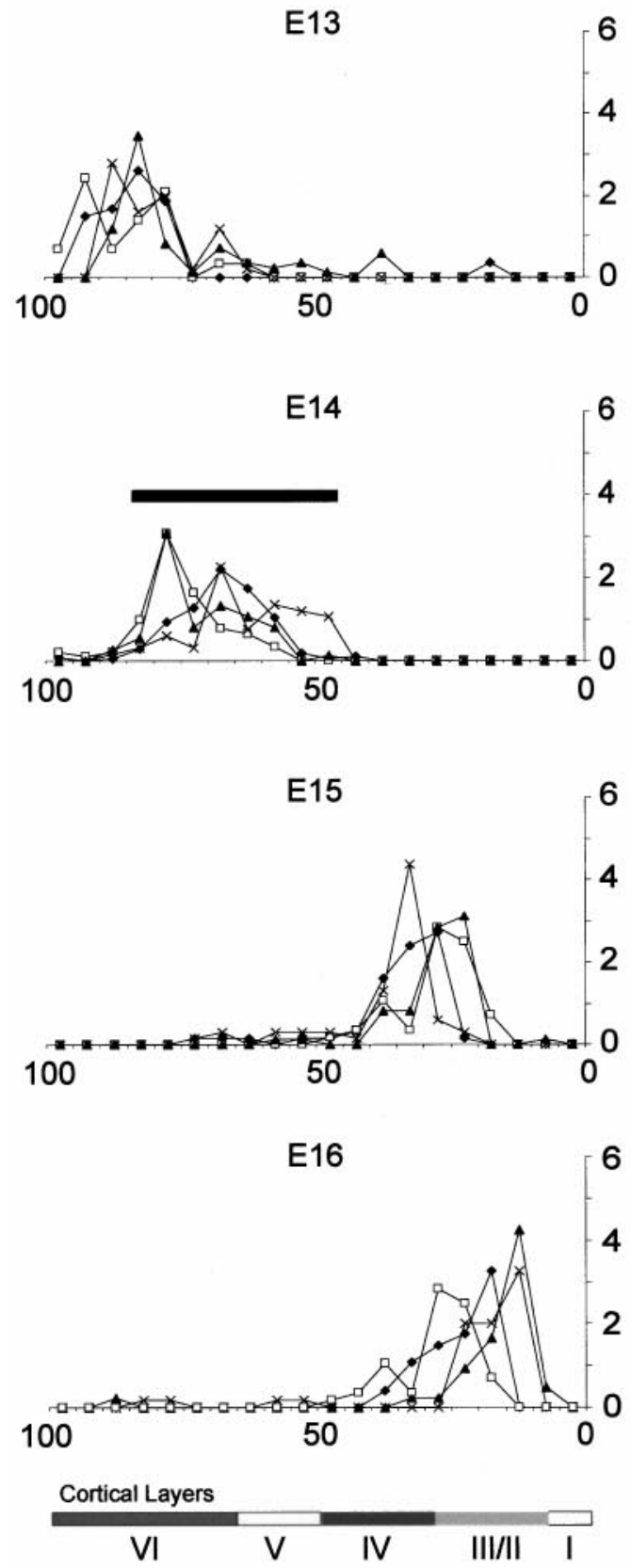

Field 40

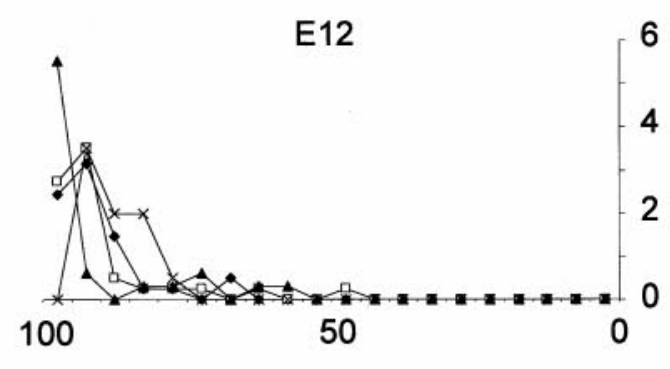

E13
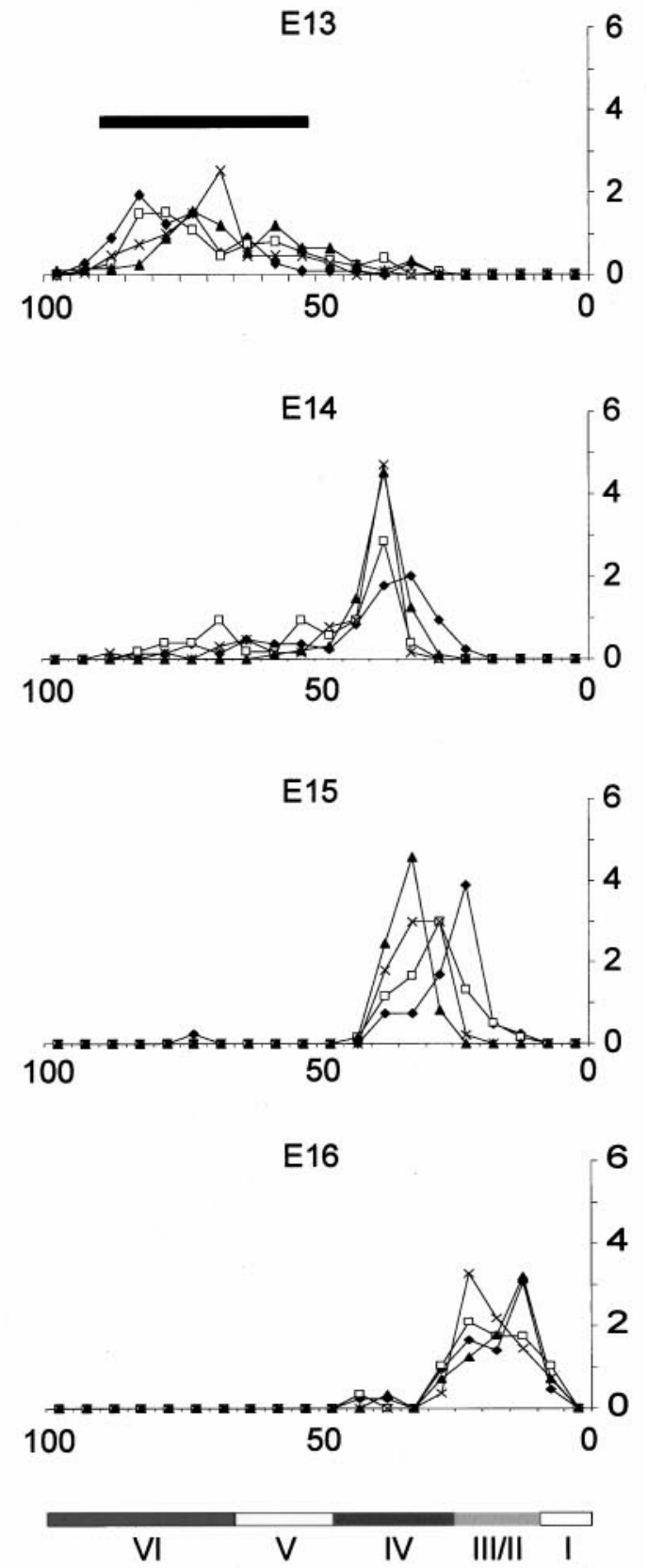

Figure 5. Animal to animal variation in neuron distribution by cohort. The distributions of the E12-E16 cohorts, normalized to percentile height, are plotted for separate animals in fields 1 (left $)$ and $40($ right $)$. The projection of the cortical layers, scaled appropriately to each field, is shown at the bottom. The distributions are essentially indistinguishable except for the cohorts distributed to midcortical layers that vary from animal to animal. These are the E13 cohort in field 40 and the E14 cohort in field 1 (bars above distributions). See Results for details. 


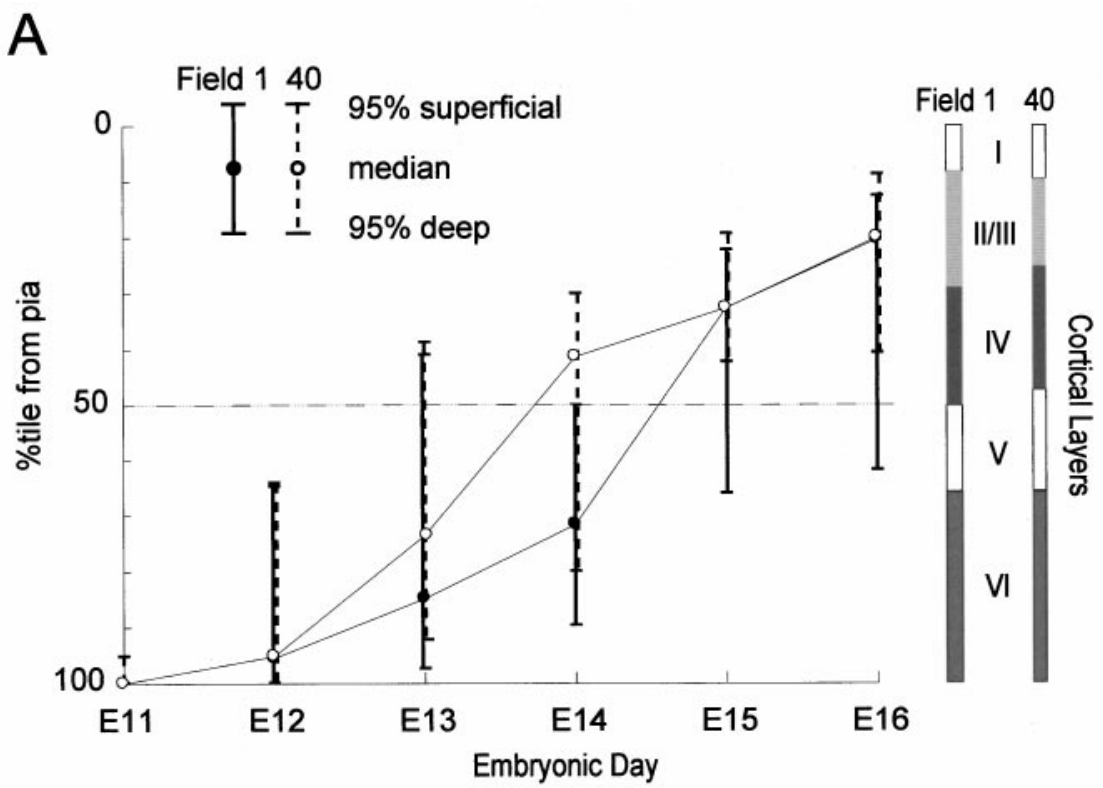

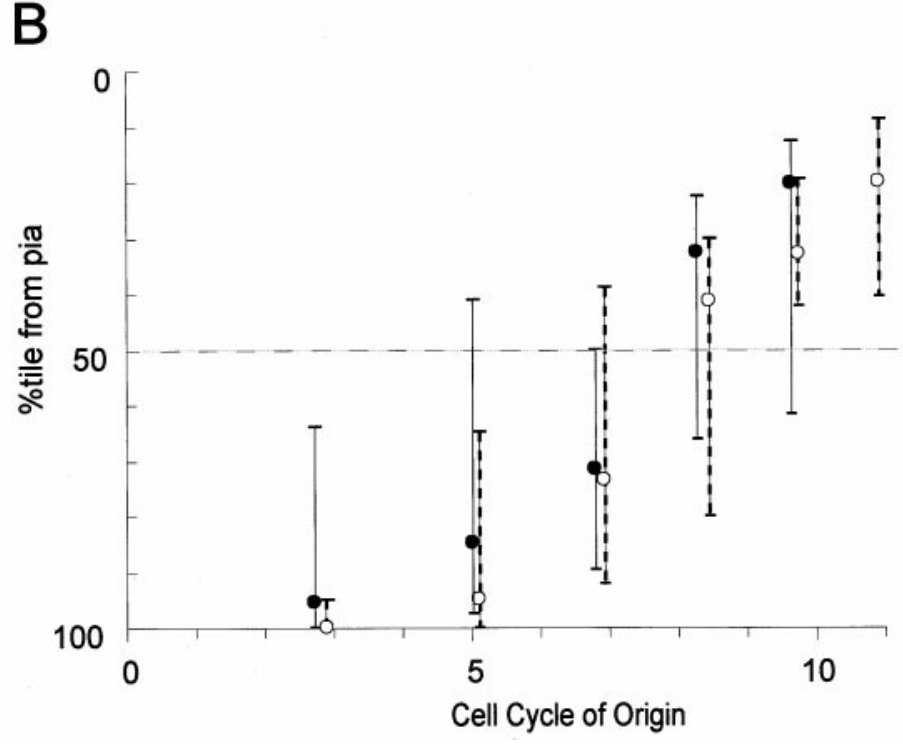

\section{Cohorts by cell cycle of origin}

Each cohort population is synchronized with respect to the time it exits $\mathrm{S}$ phase and completes the cycle before exit from the PVE (Fig. 2). The proliferative population represented by the cohort, on the other hand, is cycling asynchronously. The cycle status of each cohort is represented here as the mean cycle status of the region of the PVE from which the cohort arises, as determined by earlier analyses (Takahashi et al., 1995; Miyama et al., 1997). As noted above, the distribution of the E13 cohort in field 40 matches closely that of the E14 cohort in field 1. An earlier analysis (Miyama et al., 1997) had established that both the E13 cohort in field 40 and the E14 cohort in field 1 arise with the seventh cycle of the 11-cycle series that constitutes the murine neuronogenetic interval. Their cycle status is designated cycle 6.9 (E13 cohort in field 40) and cycle 6.8 (E14 cohort in field 1) because the population of origin will have completed 90 and $80 \%$, respectively, of the seventh cycle in the series of 11 cycles (Takahashi et al., 1995; Miyama et al., 1997).
Field 140

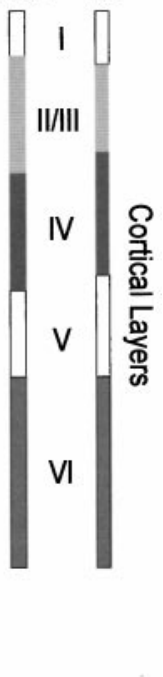

Figure 6. Intracortical distribution presented as median and range that contains $95 \%$ of the cells in each 2 hr cohort. Distributions within fields 1 and 40 are mapped for each embryonic day with respect to cortical height expressed as percentile (on the ordinate). The $95 \%$ range of distributions is some $22-56 \%$ of the cortical height. Note that an E11 cohort is present only in field 40. The distributions of E13 and E14 cohorts diverge sharply in fields 1 and $40(A)$. By contrast, the distributions of cohorts with respect to cell cycle of origin $(B)$ are closely similar in the two cortical fields. The bars on the right show the laminar borders for each cortical area.

When the birth of cohorts is normalized in this way to cell cycle of origin (Fig. 6, compare $A, B$ ), it becomes apparent that the correspondence in the intracortical distributions in fields 40 and 1 is in good accord for the entire series of cohorts. The accord is particularly good for cohorts arising through cycle 7, which in both fields are distributed in overlapping deep to superficial order within the infragranular layers VI-V. The cohorts arising at the end of the neuronogenetic interval, i.e., with cycles $8-11$, are similarly distributed to granular and supragranular layers in both fields 1 and 40, although those in the latter field appear to be positioned slightly more deeply than those in field 1 .

\section{Output per cell cycle}

The net output sampled in each cohort (Fig. $4 A$ ) is adjusted to net output per cycle by multiplying by $T_{\mathrm{C}} / 2$ for the respective cycle (Fig. 4B) (see Materials and Methods). Then, a normal distribution was "fit" to the net output per cycle for each cohort. These normal distributions account for $86-100 \%$ of the observed vari- 
Field 1

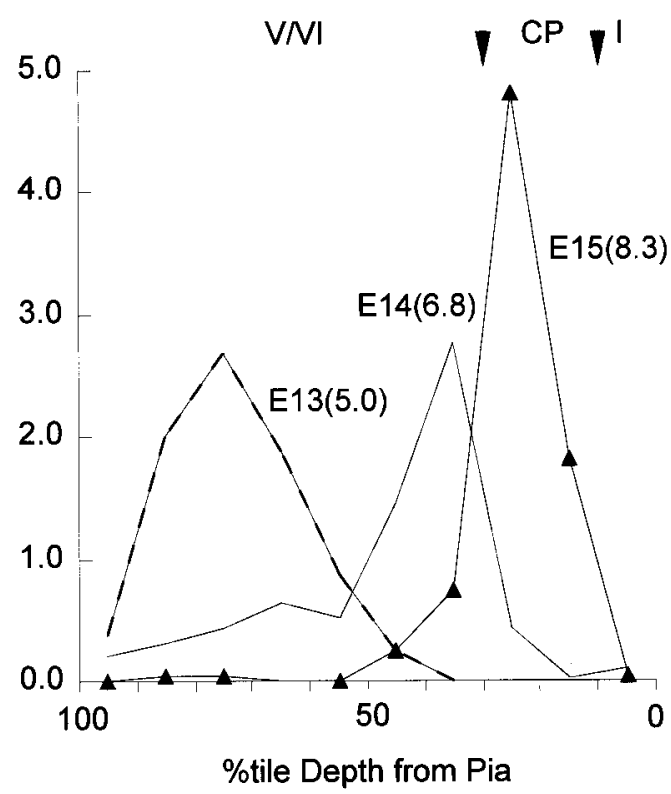

Field 40

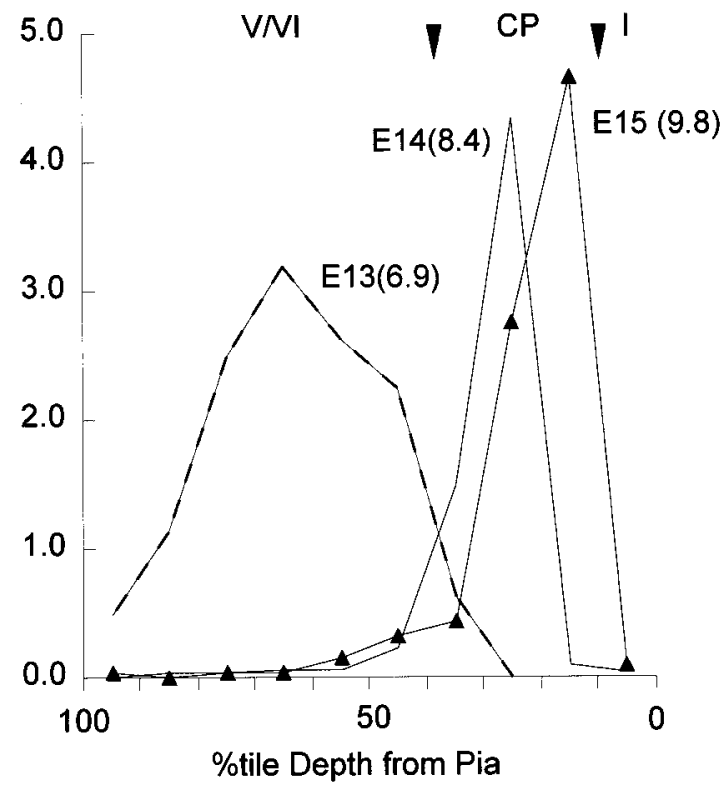

Figure 7. Intracortical distributions of cohorts of cells arising on E13-E15 determined at P0. The cortical plate (CP, between two arrowheads) at P0 corresponds to layers II/III-IV at P22. Note that the distribution pattern of each cohort at P0 is essentially identical to that at $\mathrm{P} 22$ (Fig. $4 A$ ).

ance "fitted" (Fig. 4C) (see Materials and Methods). Overall only $\sim 6 \%$ of all cells were not accounted for by the normal fits, and the only cycle for which a normal fit accounts for $<90 \%$ of the variance is for the E14 cohort in cortical field 1 (for which $R^{2}=$ 0.86). As mentioned earlier in this manuscript (Embryo-toembryo variation in cohort distribution in fields 40 and 1), this cohort represents the neurons for the mid-region of the cortex (that is, upper layer VI, layer V, and layer IV) where relatively large differences in laminar distribution are probably associated with relatively small differences in maturity of the sampled specimens (Fig. 5). Although normal distributions are close fits for the observed distributions of the set of cohorts, these fits are, as noted, not perfect. Each is slightly skewed with respect to a true normal distribution. The observed skew is not systematic, however, in that it is sometimes toward the depth and sometimes toward the surface of the cortex; a plot of the residuals (data not shown) confirms the impression that the cells falling outside of the fit to normal distributions are not located in any systematic location in the cortex.

The portion of the cells ( $\sim 6 \%$ of the total arising from all cycles) falling outside of the normalized fit may represent "biological noise," for example corresponding, as noted above, to small differences in relative maturity of the embryos of the same litter (Fig. 5). They also may simply reflect limits of the precision of the total set of mechanisms that appoint the laminar positions of neurons in the cortex. We also consider the possibility that certain of the neurons with positions outside of the best-fit normal distribution may arise from proliferative sources outside of the neocortical PVE. For example, substantial numbers of GABAergic interneurons may be formed in the ganglionic eminence rather than in the neocortical PVE (De Carlos et al., 1996; Anderson et al., 1997; Tamamaki et al., 1997; Lavdas et al., 1998; Meyer et al., 1998). Immigrant neurons of a cohort such as these, in numbers that are small relative to those arising in the neocortical PVE (of the order of $6 \%$ of the respective cohort), would reach the cortex on different schedules and by means of guidance mechanisms quite different from those arising in the neocortical PVE. As a consequence they might be systematically shifted in their intracortical positions away from the mean cohort position of the cells arising in the PVE. That is, the $2 \mathrm{hr}$ cohort tracking method will not distinguish among intracortical neurons generated at the same time in different locations.

\section{Proportionate output by cycle to layers}

We have approximated by linear interpolation of the normal fits the output and its distribution for each cell cycle of the full 11-cycle neuronogenetic sequence (Fig. 4D) (see Materials and Methods). We have then used this estimated output for each cell cycle to estimate the proportional and numerical contributions of each cycle to the full cortex and to each cortical layer in fields 1 and 40 (Figs. 8, 9).

The principal generalization is that the distribution of neurons arising with each successive cycle is highly concordant with respect to neocortical layer in fields 40 and 1, although there are significant differences in the relative contributions of cycles to given layers in the two fields. As a general overview, there is an increasing neuronal net output with advance through the 11 cycles. This is to be expected from the estimates of total output (i.e., before histogenetic cell death) from source PVE (Takahashi et al., 1996a). The infragranular layers (layers VI and V) in both fields 40 and 1 consume some $30 \%$ of this output from source, and this fraction is contributed by the initial 8 of the 11 (or nearly $75 \%$ ) of the total cell cycles. By contrast, granular and supragranular layers (layers IV and II/III, respectively), although collectively consuming some $70 \%$ of the output from source PVE, receive this from only the three terminal cell cycles. Moreover, this accelerating pattern of output from source is fully in accord with the quantitative impressions from numerous birthday studies 


\section{Field 1}

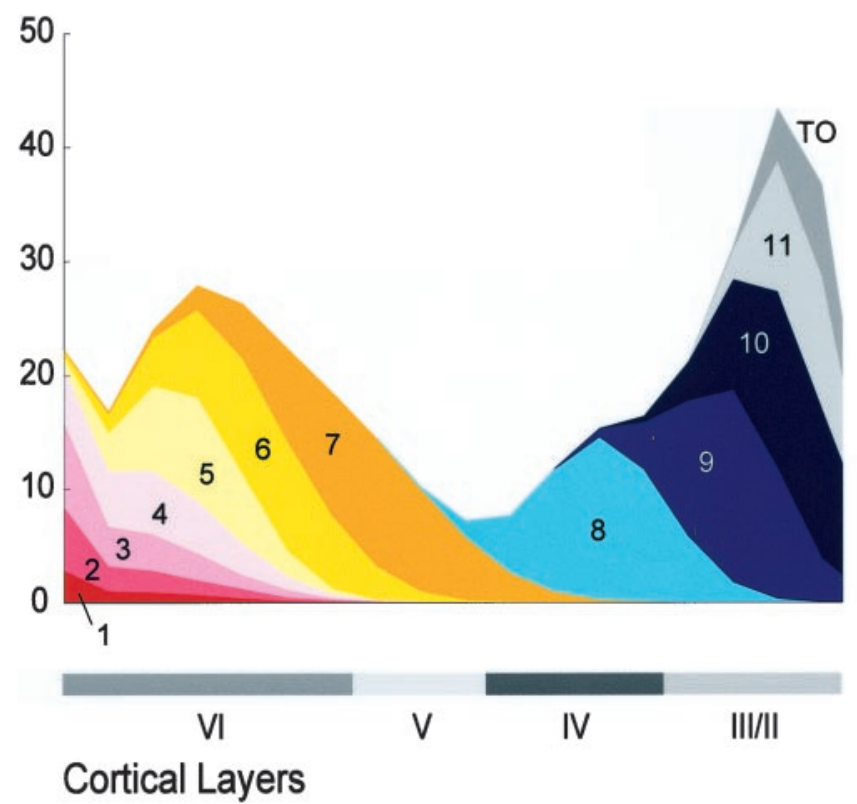

Field 40

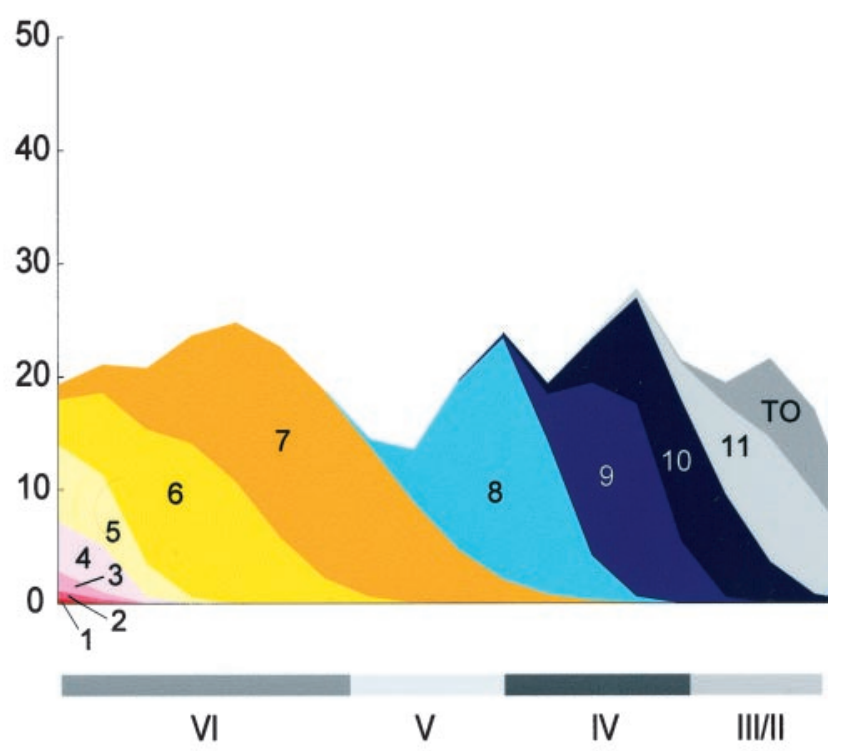

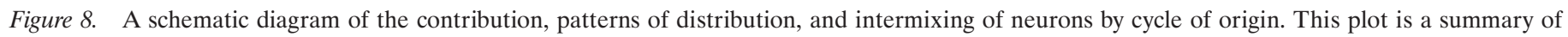

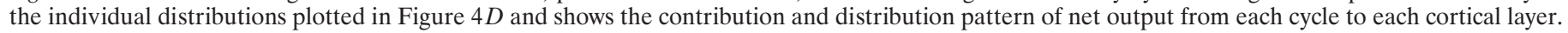

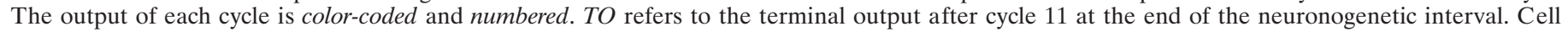

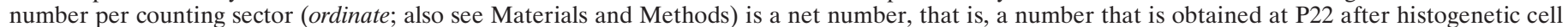

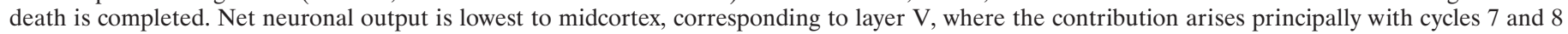
in both fields. It is evident that all layers, and particularly the deepest levels of layer VI, represent the contributions of many cycles.

in a broad range of species. Such studies have emphasized the surge of neuronal output later in the neuronogenetic interval (Hicks and D'Amato, 1968; Fernandez and Bravo, 1974; Rakic, 1974; Bisconte and Marty, 1975b; McSherry, 1984; Luskin and Shatz, 1985; Bayer and Altman, 1991).

With respect to the distribution of cycle output to neocortical layers, each layer represents a mixture of neurons arising from two or more cycles (Figs. 8, 9B). Cycles 7-10, the principal contributors to the cortical neuronal population, give rise to cells that are distributed over two or more layers. Conversely, the neuronal contributions of the initial six cycles are confined to the height of layer VI, whereas that of terminal cycle 11 is essentially limited to layer II/III (Fig. 9A).

\section{Numerical output to layers in relation to cycle of origin}

The net output of the full series of 11 cell cycles to each of the two neocortical fields, estimated by the linear interpolation (Figs. $4 D, 8)$, is virtually identical (398 in field 40 and 382 in field 1). That is, the estimated net output for all cell cycles in the two fields differs only by $\sim 5 \%$. Thus, the present estimate of net output to the two cortical fields in the course of the 11 cycles of the neuronogenetic interval is on the order of 400 cells subtended by $1000 \mu \mathrm{m}^{2}(250 \times 4 \mu \mathrm{m})$ of pial surface or $4 \times 10^{5}$ cells subtended by $1 \mathrm{~mm}^{2}$ of pial surface. Elsewhere we have obtained a similar estimate by direct counts (Goto et al., 1999).

Our estimates in mouse, obtained by these different methods, compare with values of up to $2 \times 10^{5}$ cells subtended by $1 \mathrm{~mm}^{2}$ of pial surface obtained in the murine neocortex by direct counting procedures (Leuba et al., 1977; Schüz and Palm, 1989). The somewhat higher estimate obtained in our analyses may reflect the fact that our calculations include the contributions of the cycles at the initiation and termination of the neuronogenetic interval. These were not directly measured here but were estimated and used to calculate the cycle-by-cycle output distributions. All of these cells appear to be essentially eliminated by cell death (Spreafico et al., 1995) and therefore would not have figured in estimates based on direct counts. In contrast to the foregoing estimate of total cells subtended by $1 \mathrm{~mm}^{2}$ of pial surface, our estimates of the relative proportion of neurons contributed to each layer in fields 40 and 1 by the full series of cycles is in close accord with the number of neurons in each layer as a proportion of the total in layers II/III-VI as estimated by direct cell counts (Leuba et al., 1977). This accord suggests that the sampling and reconstruction procedures undertaken in this manuscript estimate the actual composition of fields 1 and 40 of the mouse neocortex reasonably faithfully.

\section{DISCUSSION}

The cytological character of the cells of the PVE remains homogeneous throughout the neuronogenetic interval. The proliferative output, by contrast, is represented by multiple neuronal classes, distinguished by both criteria of morphology and connectivity. We demonstrate here that cohorts of neurons arising from a small fraction of a single cell cycle and from the same region of the PVE may have different laminar fates in the cortex. Although arising from a small fraction of a single cell cycle, the neurons of each cohort become widely dispersed in the cortex where they become intermixed with neurons arising during both previous and subsequent cell cycles. These observations have implications for mechanisms that govern the sequencing of neuronogenetic events in the PVE and those that govern the postmigratory distribution of neurons within cortex. 
A

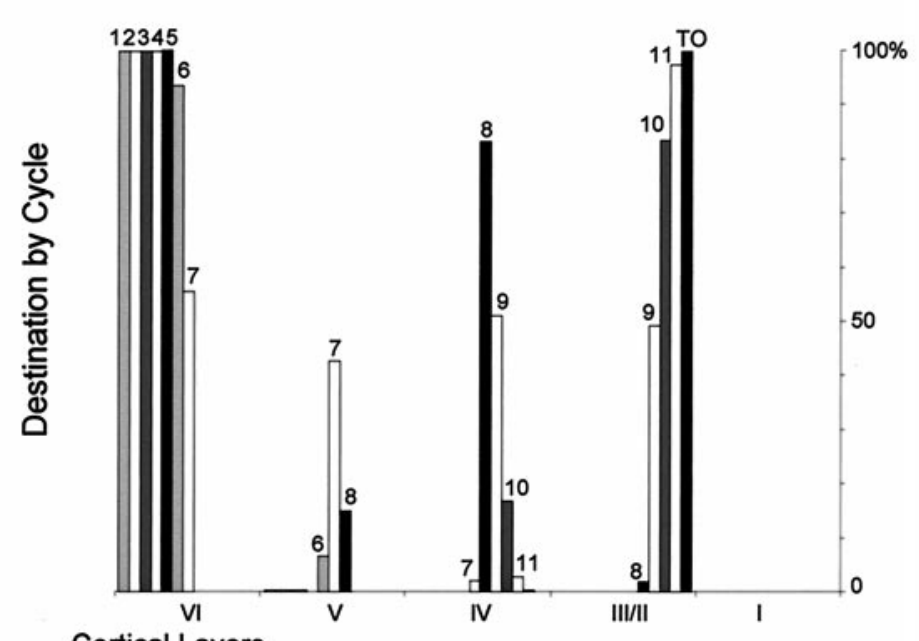

Cortical Layers

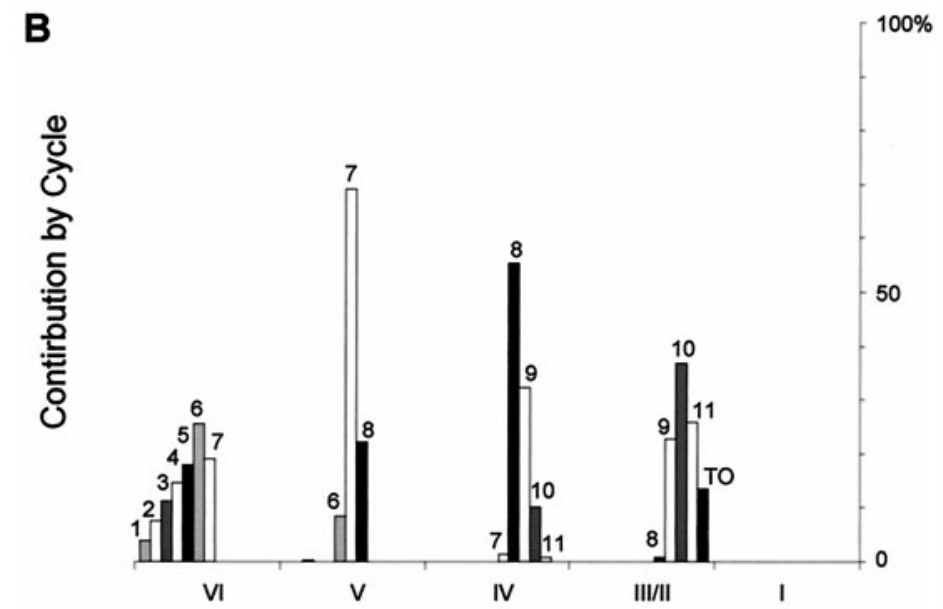

Field 1

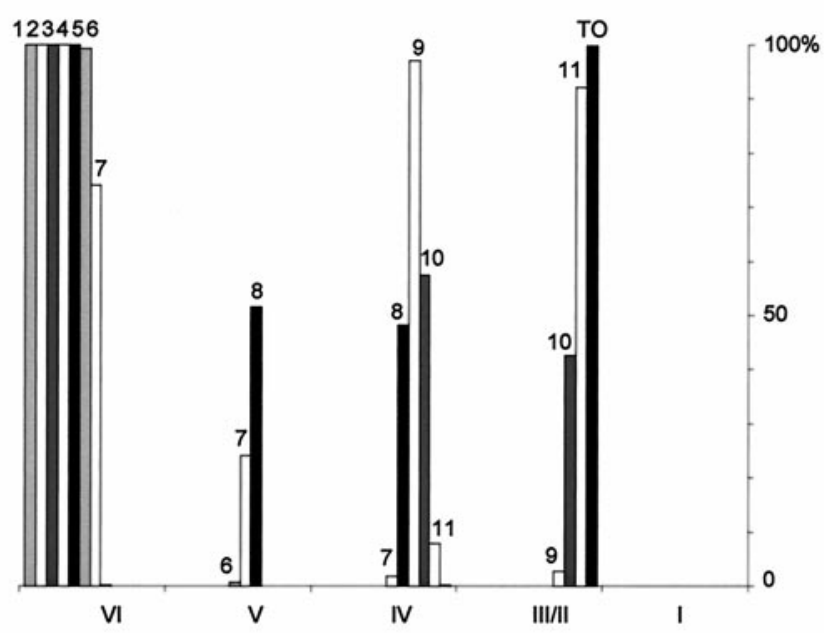

Figure 9. A summary of the cell cycle of origin of neurons for each cortical layer. $A$, The proportion of the output of each cycle (cycle numbers at the top of each histogram), expressed as percentage (ordinate), is plotted with respect to layer of destination (abscissa) for fields 1 (left) and 40 (right). Virtually $100 \%$ of the output of cell cycles 1-6 is distributed exclusively in layer VI in both fields, but the output of cycles 7-11 goes to multiple layers. $B$, The proportion of its cells, expressed as percentage (ordinate), that each layer receives from each of the 11 cycles of neuronogenesis. Each of the cortical layers receives output from multiple cell cycles.

\section{Neuronogenetic sequence in PVE is correlated with cell cycle}

Cell cycle sequence, in contrast to the flow of embryonic time, is established here to be a sensitive correlate of neuronogenetic sequence. That is, the neurons of corresponding laminar distribution arise with the corresponding sequence of cycles of the 11-cycle series, independently of whether in field 1 or 40 and when (embryonic time) their origin actually occurs. Moreover, the length of $\mathrm{G} 1$ phase $\left(T_{\mathrm{G} 1}\right)$, the regulated kinetic parameter, and $Q$ (or $Q$ fraction), the regulated output parameter, are also strongly correlated with cell cycle sequence independently of region of the PVE (Takahashi et al., 1995, 1996a; Miyama et al., 1997). Because neuronogenetic events (i.e., those that determine laminar fate) and proliferative parameters $\left(T_{\mathrm{G} 1}\right.$ and $\left.Q\right)$ are coordinated in this way by cell cycle sequence, it is plausible that they share common regulatory mechanisms. That is, it is plausible that those mechanisms that specify neuronal laminar fate are not only coordinate with but are dependent on those mechanisms that regulate the proliferative parameters of the advancing sequence of cell cycles (Caviness et al., 1999).

The temporal resolution of the $2 \mathrm{hr}$ cohort labeling method used in this analysis is $1.5 \%$ of the neuronogenetic interval, i.e., $\sim 10$ - to 20 -fold greater than the standard birthday protocols (see Materials and Methods). If neurons settled in the cortex in the same precise sequence as their birth hour, each cohort would occupy only $1.5 \%$ of the cortical thickness. Depending on the cohort, this output is distributed instead through $>22-56 \%$, with a mean of $41 \%$ of the cortical height. This degree of dispersion is some 27 times greater than expected if sequence of origin were the sole determinant of position. In addition, because the final configuration of the cortex is highly orderly with neurons sorted systematically by class into layers and sublayers, the broad dispersion of single cohorts indicates that neurons destined for different layers and representative of different classes arise with the same 
cycle. Thus, it is evident that cell cycle of origin alone is also not sufficient to specify uniquely either laminar position or cell class. Likewise, the kinetics of the cycle of origin is seen to be insufficient to specify laminar destination, whatever role these parameters may have in the determination of regional neocortical distinctions (Dehay et al., 1993; Miyama et al., 1997; Polleux et al., 1997a,b).

The degree of dispersion of single cohorts and the degree of intermixing of multiple sequential cohorts determined by the present method is similar, in fact, to that observed in certain cortical regions in monkey (Rakic, 1974, 1976, 1982; Granger et al., 1995). As previously noted in Materials and Methods, the approximate temporal resolution of the standard ${ }^{3} \mathrm{H}$-TdR pulse in monkey will be $\sim 1 \%$ of the total neuronogenetic interval. For example, the cells born on E45-E50 in monkey are distributed across layers VI-IV in the Rolandic cortex (Rakic, 1982), whereas those born on E55 span layers VI-III in field 24 (Granger et al., 1995). Thus, the degree of dispersion of cohorts arising through comparable fractions of the neuronogenetic interval is closely similar in species as disparate in size, gestational interval, and organizational complexity as mouse and monkey. This suggests that those mechanisms that relate time of origin to cortical laminar distribution are under similar regulatory controls.

\section{Specification of neuronal class and cell cycle sequence}

The layers of the neocortex, and other cortical structures, represent a sorting of neuronal somata by class. This suggests that laminar fate of neurons is determined in some way by properties of cell class (McConnell, 1989; McConnell and Kaznowski, 1991). The mechanism of neuronal sorting by class into layers is not well understood but depends, presumably, on positional relationships that form between the neuron and its afferent axonal bed (Caviness and Rakic, 1978; Pinto-Lord and Caviness, 1979).

Mechanisms that determine neuronal class in the course of the proliferative process are equally obscure (Alexiades and Cepko, 1997; Chang and Harris, 1998; Perron et al., 1998). Because laminar fate is found here to correlate with cell cycle of origin, it follows that the determination of neuronal fate is also correlated with cycle of origin. The correlation is certainly systematic but only approximate. It is as though a narrow cell-class "band width filter" ascends a specified sequence of class options with progression through the 11-cycle sequence of the neuronogenetic interval. The height of the window of the filter is always wider than the band corresponding to a single class, but the multiple classes that are admitted must be classes that are within the sequence continuum. For example, in the course of cycles 1-6, the window would be open to classes native to layer VI but closed to those of overlying layers. In the course of cycles 9-11, the window would be open to classes native to layers II/III but closed to those of deeper layers. Within the class range viewed by the open window at a given cycle, the probability of class might have its unique threshold of expression among cells arising from that cycle. Whatever the nature of these mechanisms, the sequence of production followed by the phenomenon of dispersion must reflect their action. Specifically, the degree of dispersion must reflect the amount of relative displacement necessary to position neurons of a class, arising and migrating with sequential cycles, with neurons of common class in a common laminar array.

It is clear, moreover, that the processes that act to disperse and sort neurons with respect to their sequence of origin and class act virtually from the time the neurons leave the proliferative epi- thelium. Thus, for E14 in mouse, cohorts arising over $2 \mathrm{hr}$ are distributed at the outset of migration over a span of intermediate zone that is three- to fivefold what would be expected solely from the length of the interval over which they arise (Takahashi et al., 1996b). Moreover, this degree of dispersion is maintained as the cells migrate into the CP (Takahashi et al., 1996b). The observations presented here indicate that there is an additional increase in dispersion of between four- and sixfold during the additional steps required for cohorts to complete their migrations into outer levels of the $\mathrm{CP}$ and their postmigratory positional rearrangements into laminae.

\section{Cell cycle sequence, cell class, and cortical histogenesis}

Current evidence favors the view that cell class specification is an event that occurs during the proliferative process in the PVE (Caviness and Rakic, 1978; McConnell, 1988; McConnell, 1989; Walsh and Cepko, 1990; Mione et al., 1994, 1997; Kornack and Rakic, 1995; Alexiades and Cepko, 1997; Chang and Harris, 1998; Perron et al., 1998). We suggest that with advance through the cell cycle succession, the transcriptional profiles of all cells advance in a way that simultaneously partially limits the range of allowable cell classes, but yet allows for each daughter cell to select from a range of cell class options that are seen to arise with that cycle. The final class choice for a specific cell of the PVE would occur by chance (i.e., perhaps influenced by competition for cell external factors) and be governed by mechanisms that set the gains for the probability of that choice for that cycle. This illusive specification process, whatever its nature, must be viewed as an event of singular importance to neocortical histogenesis. This is because ultimately it is the consequences of the class specification process that assure the laminar structure of the neocortex (McConnell, 1988, 1989).

The mechanisms that ultimately position cells by class in appropriate laminar order act only after the neuron has initiated its movement away from the epithelium of origin and entered the developing cortex. These positioning events and those of cell death (Finlay and Pallas, 1989; Ferrar et al., 1992; Miller, 1995; Spreafico et al., 1995; Verney et al., 1999) and synaptogenesis (Bourgeois and Rakic, 1993; Bourgeois et al., 1994; Granger et al., 1995) to follow are the principal postmigratory events of neocortical histogenesis. The regulation of these events occurring within the cortex after migration may be largely independent of those mechanisms that direct the neuronogenetic process that precedes them (Rakic et al., 1994; Verney et al., 1999).

\section{REFERENCES}

Alexiades M, Cepko C (1997) Subsets of retinal progenitors display temporally regulated and distinct biases in the fates of their progeny. Development 124:1119-1131.

Anderson S, Eisenstat D, Shi L, Rubenstein J (1997) Interneuron migration from basal forebrain to neocortex: dependence on Dlx genes. Science 278:474-476.

Angevine J (1965) Time of neuron origin in the hippocampal region: an autoradiographic study in the mouse. Exp Neurol [Suppl] 2:1-71.

Angevine JB, Sidman RL (1961) Autoradiographic study of cell migration during histogenesis of the cerebral cortex in the mouse. Nature 192:766-768.

Bayer SA, Altman J (1991) Neocortical development. New York: Raven. Bisconte J-C, Marty R (1975a) Analyse chronoarchitectonique du cerveau de rat par radioautographie. I. Histogenese du telencephale. J Hirnforsch 16:55-74.

Bisconte J-C, Marty R (1975b) Etude quantitative du marquage radioautographique dans le systeme nerveux du rat. II. Caracteristiques finales dans le cerveau de l'animal adulte. Exp Brain Res 22:37-56.

Bourgeois J-P, Rakic P (1993) Changes of synaptic density in the pri- 
mary visual cortex of the macaque monkey from fetal to adult stage. J Neurosci 13:2801-2860.

Bourgeois J-P, Goldman-Rakic PS, Rakic P (1994) Synaptogenesis in the prefrontal cortex of rhesus monkeys. Cereb Cortex 4:78-96.

Cai L, Hayes N, Nowakowski R (1997) Local homogeneity of cell cycle length in developing mouse cortex. J Neurosci 17:2079-2087.

Caviness Jr VS (1975) Architectonic map of neocortex of the normal mouse. J Comp Neurol 164:247-263.

Caviness Jr VS (1982) Neocortical histogenesis in normal and reeler mice: a developmental study based upon $[3 \mathrm{H}]$ thymidine autoradiography. Dev Brain Res 4:293-302.

Caviness Jr VS, Rakic P (1978) Mechanisms of cortical development: a view from mutations in mice. Annu Rev Neurosci 1:297-326.

Caviness Jr VS, Takahashi T, Nowakowski R (1995) Numbers, time and neocortical neuronogenesis: a general developmental and evolutionary model. Trends Neurosci 18:379-383.

Caviness Jr VS, Takahashi T, Nowakowski R (1999) Neuronogenesis and the early events of neocortical histogenesis. In: Development of the neocortex (Goffinet A, Rakic P, eds). Berlin: Springer, in press.

Chang W, Harris W (1998) Sequential genesis and determination of cone and rod photoreceptors in Xenopus. J Neurobiol 35:227-244.

De Carlos JA, Lopez-Mascaraque L, Valverde F (1996) Dynamics of cell migration from the lateral ganglionic eminence in the rat. J Neurosci 16:6146-6156.

Dehay C, Giroud P, Berland M, Smart I, Kennedy H (1993) Modulation of the cell cycle contributes to the parcellation of the primate visual cortex. Nature 366:464-466.

Fernandez V, Bravo H (1974) Autoradiographic study of the cerebral cortex in the rabbit. Brain Behav Evol 9:317-332.

Ferrar I, Soriano E, Del Rio JA, Alcantara S, Auladell C (1992) Cell death and removal in the cerebral cortex during development. Prog Neurobiol 39:1-43.

Finlay BL, Pallas SL (1989) Control of cell number in the developing mammalian visual system. Prog Neurobiol 32:207-234.

Finlay BL, Slattery M (1983) Local differences in the amount of early cell death in neocortex predict adult local specializations. Science 219:1349-1351.

Goto T, Caviness VS Jr, Nowakowski R, Takahashi T (1999) Altered pattern of neuron production in p27kip1 knockout mouse (p27ko). Soc Neurosci Abstr 25:1541.

Granger B, Tekaia F, Le Sourd A, Rakic P, Bourgeois J-P (1995) Tempo of neurogenesis and synaptogenesis in the primate cingulate mesocortex: comparison with the neocortex. J Comp Neurol 360:363-376.

Hayes N, Nowakowski R (1999) Exploiting the dynamics of S-phase tracers in developing brain: interkinetic nuclear migration for cells entering vs leaving the S-phase. Dev Neurosci, in press.

Hicks SP, D'Amato CJ (1968) Cell migration to the isocortex in the rat. Anat Rec 160:619-634.

Kornack DR, Rakic P (1995) Radial and horizontal deployment of clonally related cells in the primate neocortex: relationship to distinct mitotic lineages. Neuron 15:311-321.

Kornack D, Rakic P (1998) Changes in cell-cycle kinetics during the development and evolution of primate neocortex. Proc Natl Acad Sci USA 95:1242-1246.

Lavdas A, Grigoriou M, Pachnis V, Parnavelas J (1998) The medial ganglionic eminence is a source of the early neurons of the developing cerebral cortex. Soc Neurosci Abstr 24:282.

Leuba G, Heumann D, Rabinowicz T (1977) Postnatal development of the mouse cerebral neocortex. I. Quantitative cytoarchitectonics of some motor and sensory areas. J Hirnforsch 18:461-481.

Luskin MB, Shatz CJ (1985) Neurogenesis of the cat's primary visual cortex. J Comp Neurol 242:611-631.

McConnell SK (1988) Fates of visual cortical neurons in the ferret after isochronic and heterochronic transplantation. J Neurosci 8:945-974.

McConnell SK (1989) The determination of neuronal fate in the cerebral cortex. Trends Neurosci 12:342-349.

McConnell SK (1991) The generation of neuronal diversity in the central nervous system. Ann Rev Neurosci 14:269-300.

McConnell SK, Kaznowski CE (1991) Cell cycle dependence of laminar determination in developing neocortex. Science 254:282-285.

McSherry GM (1984) Mapping of cortical histogenesis in the ferret. J Embryol Exp Morphol 81:239-252.

McSherry GM, Smart IHM (1986) Cell production gradients in the developing ferret isocortex. J Anat 1-14.

Meyer G, Soria J, Martinez-G, Talan J, Marrtin-Clemente B, Fairen A
(1998) Different origins and developmental histories of transient neurons in the marginal zone of the fetal and neonatal rat cortex. J Comp Neurol 397:493-518.

Miller M (1995) Relationship of the time of origin and death of neurons in rat somatosensory cortex: barrel versus septal cortex and projection versus local circuit neurons. J Comp Neurol 355:6-14.

Mione MC, Danevic C, Boardman P, Harris B, Parnavelas JG (1994) Lineage analysis reveals neurotransmitter (GABA or glutamate) but not calcium-binding protein homogeneity in clonally related cortical neurons. J Neurosci 14:107-123.

Mione MC, Cavanagh J, Harris B, Parnavelas J (1997) Cell fate specification and symmetrical/asymmetrical divisions in the developing cerebral cortex. J Neurosci 17:2018-2029.

Misson J-P, Austin C, Takahashi T, Cepko C, Caviness Jr VS (1991) The alignment of migrating neural cells in relation to the murine neopallial radial glial fiber system. Cereb Cortex 1:221-229.

Miyama S, Takahashi T, Nowakowski RS, Caviness Jr VS (1997) A gradient in the duration of the G1 phase in the murine neocortical proliferative epithelium. Cereb Cortex 7:678-689.

Perron M, Kanekar S, Vetter M, Harris W (1998) The genetic sequence of retinal development in the ciliary margin of the Xenopus eye. Dev Biol 199:185-200.

Pinto-Lord MC, Caviness Jr VS (1979) Determinants of cell shape and orientation: a comparative Golgi analysis of cell-axon interrelationships in the developing neocortex of normal and reeler mice. J Comp Neurol 187:49-69.

Polleux F, Dehay C, Kennedy H (1997a) The timetable of laminar neurogenesis contributes to the specification of cortical areas in mouse isocortex. J Comp Neurol 385:95-116.

Polleux F, Dehay C, Moraillon B, Kennedy H (1997b) Regulation of neuroblast cell-cycle kinetics plays a crucial role in the generation of unique features of neocortical areas. J Neurosci 17:7763-7783.

Rakic P (1972) Mode of cell migration to the superficial layers of fetal monkey neocortex. J Comp Neurol 145:61-84.

Rakic P (1974) Neurons in rhesus monkey visual cortex: systematic relation between time of origin and eventual disposition. Science 183:425-427.

Rakic P (1976) Differences in the time of origin and in eventual distribution of neurons in areas 17 and 18 of visual cortex in Rhesus monkey. Exp Brain Res [Suppl] 1:244-248.

Rakic P (1978) Neuronal migration and contact guidance in the primate telencephalon. Postgrad Med J 54:25-40.

Rakic P (1981) Developmental events leading to laminar and areal organization of the neocortex. In: The organization of the cerebral cortex (Schmitt FO, Worden FG, Adelman G, Dennis SG, eds), pp 7-28. Cambridge, MA: MIT.

Rakic P (1982) Early developmental events: cell lineages, acquisition of neuronal positions and areal and laminar development. Neurosci Res Prog Bull 20:439-452.

Rakic P, Bourgeois J-P, Goldman-Rakic PS (1994) Synaptic development of the cerebral cortex: implications for learning, memory and mental illness. In: The self-organizing brain: from growth cones to functional networks (van Pelt J, Corner MA, Uylings HBM, Lopes da Silva FH, eds), pp 227-243. Amsterdam: Elsevier.

Rice FL, van der Loos H (1977) Development of barrels and barrel field in the somatosensory cortex of the mouse. J Comp Neurol 171:545-560.

Sauer FC (1935) Mitosis in the neural tube. J Comp Neurol 62:377-405.

Schüz A, Palm G (1989) Density of neurons and synapses in the cerebral cortex of the mouse. J Comp Neurol 286:442-455.

Sidman RL (1970) Autoradiographic methods and principles for study of the nervous system with thymidine-H3. In: Contemporary research methods in neuroanatomy (Nauta WJH, Ebbesson SOE, eds), pp 252274. New York: Springer.

Sidman RL, Miale IL, Feder N (1959) Cell proliferation and migration in the primitive ependymal zone: an autoradiographic study of histogenesis in the nervous system. Exp Neurol 1:322-333.

Smart IHM, McSherry GM (1982) Growth patterns in the lateral wall of the mouse telencephalon. II. Histological changes during and subsequent to the period of isocortical neuron production. $J$ Anat 131:415-442.

Smart IHM, Smart M (1982) Growth patterns in the lateral wall of the mouse telencephalon. I. Autoradiographic studies of the histogenesis of the iso-cortex and adjacent areas. J Anat 134:273-298.

Spreafico R, Frassoni C, Arcelli P, Selvaggio M, De Biasi S (1995) In situ 
labeling of apoptotic cell death in the cerebral cortex and thalamus of rats during development. J Comp Neurol 363:281-295.

Takahashi T, Nowakowski R, Caviness Jr VS (1992) BUdR as an S-phase marker for quantitative studies of cytokinetic behaviour in the murine cerebral ventricular zone. J Neurocytol 21:185-197.

Takahashi T, Tsai L-H, Harlow E, Caviness Jr VS (1993) Cyclin dependent kinases in the developing nervous system. Soc Neurosci Abstr 19:30.

Takahashi T, Nowakowski R, Caviness Jr VS (1994) Mode of cell proliferation in the developing mouse neocortex. Proc Natl Acad Sci USA 91:375-379.

Takahashi T, Nowakowski R, Caviness Jr VS (1995) The cell cycle of the pseudostratified ventricular epithelium of the murine cerebral wall. J Neurosci 15:6046-6057.

Takahashi T, Nowakowski R, Caviness Jr VS (1996a) The leaving or Q fraction of the murine cerebral proliferative epithelium: a general computational model of neocortical neuronogenesis. J Neurosci 16:6183-6196.

Takahashi T, Nowakowski RS, Caviness Jr VS (1996b) Interkinetic and migratory behavior of a cohort of neocortical neurons arising in the early embryonic murine cerebral wall. J Neurosci 16:5762-5776.

Tamamaki N, Fujimori K, Kakauji R (1997) Origin and route of tangentially migrating neurons in the developing neocortical intermediate zone. J Neurosci 17:8313-8323.

Theiler K (1972) The house mouse. Development and normal stages from fertilization to 4 weeks of age. Berlin: Springer.

Verney C, Takahashi T, Bhide PG, Nowakowski RS, Caviness Jr VS (1999) Independent controls for neocortical neuron production and histogenetic cell death. Dev Neurosci, in press.

Walsh C, Cepko C (1990) Cell lineage and cell migration in the developing cerebral cortex. Experientia 46:940-947. 